\title{
Hygroscopic properties of aerosol particles at high relative humidity and their diurnal variations in the North China Plain
}

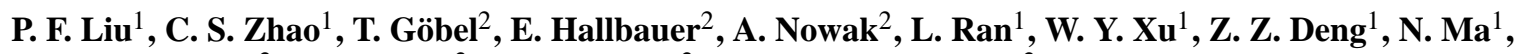 \\ K. Mildenberger ${ }^{2}$, S. Henning ${ }^{2}$, F. Stratmann ${ }^{2}$, and A. Wiedensohler ${ }^{2}$ \\ ${ }^{1}$ Department of Atmospheric and Oceanic Sciences, School of Physics, Peking University, Beijing, 100871, China \\ ${ }^{2}$ Institute for Tropospheric Research, Permoserstr. 15, 04318 Leipzig, Germany
}

Received: 5 January 2011 - Published in Atmos. Chem. Phys. Discuss.: 26 January 2011

Revised: 12 April 2011 - Accepted: 12 April 2011 - Published: 14 April 2011

\begin{abstract}
The hygroscopic properties of submicron aerosol particles were determined at a suburban site (Wuqing) in the North China Plain among a cluster of cities during the period 17 July to 12 August, 2009. A High Humidity Tandem Differential Mobility Analyser (HH-TDMA) instrument was applied to measure the hygroscopic growth factor (GF) at $90 \%$, $95 \%$ and $98.5 \%$ relative humidity $(\mathrm{RH})$ for particles with dry diameters between 50 and $250 \mathrm{~nm}$. The probability distribution of GF (GF-PDF) averaged over the period shows a distinct bimodal pattern, namely, a dominant more-hygroscopic $(\mathrm{MH})$ group and a smaller nearly-hydrophobic $(\mathrm{NH})$ group. The MH group particles were highly hygroscopic, and their GF was relatively constant during the period with average values of $1.54 \pm 0.02,1.81 \pm 0.04$ and $2.45 \pm 0.07$ at $90 \%$, $95 \%$ and $98.5 \% \mathrm{RH}\left(D_{0}=100 \mathrm{~nm}\right)$, respectively. The $\mathrm{NH}$ group particles grew very slightly when exposed to high RH, with GF values of $1.08 \pm 0.02,1.13 \pm 0.06$ and $1.24 \pm 0.13$ respectively at $90 \%, 95 \%$ and $98.5 \% \mathrm{RH}\left(D_{0}=100 \mathrm{~nm}\right)$. The hygroscopic growth behaviours at different RHs were well represented by a single-parameter Köhler model. Thus, the calculation of GF as a function of RH and dry diameter could be facilitated by an empirical parameterization of $\kappa$ as function of dry diameter. A strong diurnal pattern in number fraction of different hygroscopic groups was observed. The average number fraction of $\mathrm{NH}$ particles during the day was about $8 \%$, while during the nighttime fractions up to $20 \%$ were reached. Correspondingly, the state of mixing in terms of water uptake varied significantly during a day. Simulations using a particle-resolved aerosol box model (PartMCMOSAIC) suggest that the diurnal variations of aerosol hygroscopicity and mixing state were mainly caused by the evolution of the atmospheric mixing layer. The shallow nocturnal boundary layer during the night facilitated the accumu-
\end{abstract}

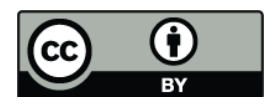

Correspondence to: C. S. Zhao (zcs@pku.edu.cn) lation of freshly emitted carbonaceous particles (mainly hydrophobic) near the surface while in the morning turbulence entrained the more aged and more hygroscopic particles from aloft and diluted the $\mathrm{NH}$ particles near the surface resulting in a decrease in the fraction of $\mathrm{NH}$ particles.

\section{Introduction}

The North China Plain is a polluted area with great industrial activity and dense population. A group of megacities (so-called city cluster) including Beijing and Tianjin is located in this region. Along with the rapid economic growth and increase in traffic during the last decades, the consumption of fossil fuels like coal, gasoline, diesel and natural gas has increased dramatically in China. The combustion of fossil fuels emits large amounts of particulate and gaseous pollutants into the atmosphere, leading to substantial environmental problems. Industrial and traffic related primary emissions, as well as the formation of secondary aerosols, combined with the transport of dust from the desert region, result frequently in heavy aerosol loads in this area depending on the meteorological conditions (Wehner et al., 2004, 2008; Liu et al., 2009). Air quality is significantly influenced by aerosol particles and high loads of aerosol pollution severely degrade visibility, especially at high RH in summer (Zhang et al., 2010); related health risks are increased as well (Leitte et al., 2011). Moreover, aerosol particles influence the earth's radiative budget directly by scattering and absorbing solar radiation (Charlson et al., 1992), and indirectly by serving as nuclei for cloud formation (Twomey, 1974; Albrecht, 1989). Aerosols may also affect the hydrological cycle (Menon et al., 2002). A study shows that the magnitude of precipitation in the North China Plain has decreased significantly during the last 40 years and that the reduction of precipitation is strongly correlated to the high concentration of aerosol particles (Zhao et al., 2006b). 
In order to reduce the uncertainties in model projections of climate change induced by aerosol indirect effects, intensive aircraft measurement studies on warm cloud microphysical properties were conducted in the areas of high aerosol loading, such as the North China Plain (Zhao et al., 2006a; Deng et al., 2009). The aerosol hygroscopic properties are very crucial for the understanding of the aerosol effects on climate via their effects on clouds, since the hygroscopic growth measured at subsaturation is closely related to the ability of aerosol particles to activate and form cloud droplets (Swietlicki et al., 2008; Rissler et al., 2010).

Moreover, hygroscopic particles grow significantly in size at high RH due to water uptake, and hence influence the aerosol optical properties, such as extinction, visibility and aerosol optical depth (AOD) (Cheng et al., 2008). Inadequate characterization of aerosol hygroscopic properties will induce large uncertainties in the estimation of aerosol direct effect on the climate.

Hygroscopic properties of aerosol particles can be determined by their physical and chemical characteristics (Topping et al., 2005a, b). The Köhler equation is often used to describe both the hygroscopic growth and the activation of aerosol particles to cloud droplets, based on the aerosol's physicochemical properties (Köhler, 1936). However, these detailed properties are not always available for ambient aerosols. Size-dependent mixing states of various chemical compositions also increase the complexity. Recently, several single-parameter schemes have been proposed to simplify the Köhler equation. Hygroscopicity parameters such as $\kappa$ and $\rho_{\text {ion }}$ have been defined as proxies of chemical composition to represent aerosol hygroscopic growth as well as the ability of aerosol particles to become cloud condensation nuclei (CCN) (Petters and Kreidenweis, 2007; Wex et al., 2007). Moreover, Rissler et al. (2010) recently overviewed several models which describe the aerosol hygroscopicity and the $\mathrm{CCN}$ activation. It is worth noting that the hygroscopicity parameter ( $\kappa$ or $\left.\rho_{\text {ion }}\right)$ for the Köhler model is not always a constant with respect to RH, especially for the range of RH above $90 \%$. This parameter is linearly proportional to the number of soluble entities per dry volume. Laboratory studies using LACIS (Leipzig Aerosol Cloud Interaction Simulator) observed an increased hygroscopicity parameter by a factor of 4-6 for secondary organic aerosol (SOA) in the RHrange from below $90 \%$ to $99.6 \%$ (Wex et al., 2009; Petters et al., 2009), indicating a significant increase in the number of soluble entities per dry volume as the RH increases at high RH. The RH-dependency of $\kappa$ could be crucial for the prediction of $\mathrm{CCN}$ number concentration. For ambient aerosols, validations of the applicability of single-parameter simplification at RH above $90 \%$ through field measurements using humidified tandem differential mobility analyser (H-TDMA) technique are necessary and are rarely reported in the current literature.

Ambient aerosols are external and internal mixtures of particles with different chemical compounds such as soot, sul- phate, nitrate, organic carbon and mineral dust. The state of mixing of these components is crucial for understanding the role of aerosol particles in the atmosphere. In recent years, much attention has been paid to the mixing state of soot in aerosols (Jacobson, 2001; Moffet and Prather, 2009; Riemer et al., 2009, 2010; Zhang et al., 2008; Oshima et al., 2009), which influences the optical properties and climate effects of aerosols. The hygroscopicity of aerosol particles can be considered as an agent of chemical composition. A Humidified Tandem Differential Mobility Analyser (H-TDMA) is one of the few instruments capable of providing information regarding the mixing state in terms of hygroscopicity of the atmospheric aerosols (Swietlicki et al., 2008). Different modes of hygroscopic growth of ambient aerosols are often observed in the H-TDMA measurements, indicating an external mixture in terms of hygroscopicity (Swietlicki et al., 2008).

A large number of ship- and ground-based measurements for the size-resolved hygroscopic properties of ambient aerosols have been conducted worldwide using the $\mathrm{H}$ TDMA technique of which the results were summarized in a review paper by Swietlicki et al. (2008). In the North China Plain area, Massling et al. (2009) and Meier et al. (2009) recently reported the hygroscopic properties measured in Beijing city using various instruments including the H-TDMA. However, due to technical limitations, most of these conventional H-TDMA field studies were conducted at the RH ranges below $90 \%$. Detailed hygroscopic properties of atmospheric aerosols at RHs above $90 \%$ are still very scarce. Considering that the hygroscopic growth factors at high $\mathrm{RH}$ are highly sensitive to aerosol chemical composition and are more closely related to cloud droplet activation behaviours, there is a strong need to measure the detailed hygroscopic properties for ambient aerosols at RH above $90 \%$.

In this paper, we focus on measurement of the aerosol hygroscopic properties in a polluted megacity area at $\mathrm{RH}$ values above $90 \%$. The High Humidity Tandem Differential Mobility Analyser (HH-TDMA) developed by Hennig et al. (2005) was applied in the field study to determine the hygroscopic properties of ambient aerosols at $90 \%, 95 \%$ and 98.5\% RH. The hygroscopic growth factors and number fractions of different hygroscopic groups are analysed. The calculated hygroscopicity parameters $\kappa$ are presented, and the size-dependent $\kappa$ values are parameterized to facilitate the application of our result in models. The diurnal variations of aerosol mixing state revealed by detailed hygroscopic properties are also discussed, and these diurnal patterns are interpreted by modelling simulations using a state-of-the-art, particle-resolved aerosol box model PartMC-MOSAIC developed by Riemer et al. (2009). 


\section{Data and methods}

\subsection{Description of the measurement campaign}

This investigation is part of the project HaChi (Haze in China), which was conducted by the collaboration of Peking University (PKU), China and Leibniz Institute for Tropospheric Research (IFT), Germany. During an intensive field campaign in July-August 2009, the aerosol number-size distribution, hygroscopicity, size resolved and bulk CCN activation properties (Deng et al., 2011), chemical composition and optical properties (Ma et al., 2011) were measured at ground level. The period of the HH-TDMA measurements analysed in this study is between 17 July 2009 and 12 August 2009, namely, HaChi summer campaign. The HH-TDMA system was located in an air-conditioned mobile laboratory with well controlled room temperature. Air was sampled through a low flow $\mathrm{PM}_{10}$ inlet. The aerosol flow was dehumidified to a relative humidity below $30 \%$ by an automatic aerosol dryer unit (Tuch et al., 2009) on the roof of the laboratory before it entered the measurement systems.

The measurement site was situated next to the Wuqing Meteorological Station $\left(39^{\circ} 23^{\prime} \mathrm{N}, 117^{\circ} 0^{\prime} \mathrm{E}, 7.4 \mathrm{~m}\right.$ a.s.l. $)$. The site is located in the west of the town, surrounded by an area with mixed agricultural, residential and industrial land use. Figure 1 shows the location of the measurement site, nearby major cities and the distribution of 4-yr average (2005-2008) AOD derived from the Moderate Resolution Imaging Spectroradiometer (MODIS) at $550 \mathrm{~nm}$ wavelength. The contour map of AOD shown in Fig. 1 demonstrates the region of high AOD from the edge of the North China Plain (north and west of Beijing) expanding to the south and east with AOD exceeding 0.6, indicating the heavy pollution in the North China Plain. Around cities such as Beijing (with about 16 million inhabitants), Tianjin (10 million inhabitants) and Baoding (1 million inhabitants) AOD values exceed 0.8 which reflect the major anthropogenic aerosol emissions in these areas. Wuqing is a suburban district of Tianjin (with about 0.8 million inhabitants) located among a cluster of large cities. The urban areas of Beijing and Tianjin are $80 \mathrm{~km}$ to the northwest and $30 \mathrm{~km}$ to the southeast of Wuqing, respectively. Tangshan (4 million inhabitants) and Baoding are two other cities in the North China Plain $130 \mathrm{~km}$ to the northeast and $160 \mathrm{~km}$ to the northwest of Wuqing, respectively. The average AOD at Wuqing is about 0.7 , which is close to the regional average value of the large polluted area in the North China Plain. Therefore, it is an optimal site for field studies which represents an average pollution level for aerosol measurements in the megacity region. The site is thus representative of the regional polluted aerosol in the North China Plain. The site is in the GMT +08:00 time zone. All times in the paper are reported as GMT +08:00.

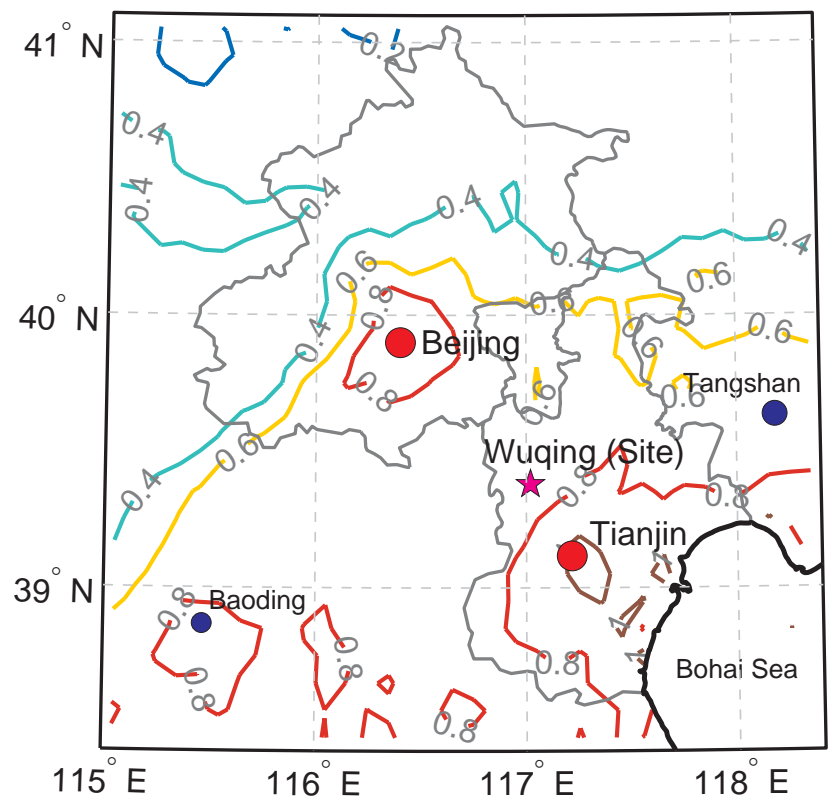

Fig. 1. Map shows the site location (red star), major cities in the vicinity (red and blue circles) and contour lines of the 4-yr average MODIS AOD (Aerosol Optical Depth) distribution (2005$2008,0.1^{\circ} \times 0.1^{\circ}$ resolution $)$

\subsection{Instrumentation and data}

\subsubsection{HH-TDMA}

The main instrument used in this study was a High Humidity Tandem Differential Mobility Analyser (HH-TDMA). The HH-TDMA was designed to measure size-resolved hygroscopic properties for laboratory and ambient aerosol at RHs between $90 \%$ and $98.5 \%$ (Hennig et al., 2005). The general principle is similar to that of the hygroscopicity tandem mobility analyser system (H-TDMA; Rader and McMurry, 1986). However, in the conventional H-TDMAsystem, the temperature fluctuations may cause instabilities of RH in the second DMA. The direct humidification has its technical limit as well, because the water vapour transport through semi-permeable membranes is limited (Hennig et al., 2005). Due to these limitations, a stable humidification of the aerosol and sheath air is difficult to maintain for RHs above $90 \%$. To measure the aerosol hygroscopicity at high RHs, the set-up of the HH-TDMA-system was re-designed to minimize the temperature fluctuation in the humidification process and in the size distribution measurement.

Similar to the H-TDMA-system, the HH-TDMA consists of two DMAs connected in series with a humidity conditioning section between them. The first DMA extracts a narrow size increment from the ambient polydisperse aerosol and is operated at $\mathrm{RH}<5 \%$. This nearly monodisperse aerosol is exposed to a well-defined, higher RH in the humidity conditioning section, and the increase of the particle size due to the 
water uptake is determined by the second DMA. Different from the conventional H-TDMA, two separate temperature controlled water baths are employed to control the temperature of humidity conditioning section and temperature of the second DMA, respectively. A constant temperature decrease of approximately $2 \mathrm{~K}$ is maintained between the second water bath (for the second DMA, operated at $20^{\circ} \mathrm{C}$ ) and the first water bath (for the humidity conditioning section, operated at $22{ }^{\circ} \mathrm{C}$ ). The humidity conditioning section can humidify the sheath air and the aerosol flow to RH values lower than $90 \%$ (about $77 \% \sim 83 \%$ in this study) by regulated mixing of dry air $(<5 \% \mathrm{RH})$ and humid air $(\sim 95 \% \mathrm{RH})$. The final RH, up to $98.5 \%$, is produced by decreasing the temperature of the second DMA relative to the humidity conditioning section. A dew point mirror (DPM) is located in the excess air line of the second DMA to measure the RH inside. Temperature and RH stability tests conducted by Hennig et al. (2005) showed that the absolute temperatures in HH-TDMA-system can be maintained within $\pm 0.1 \mathrm{~K}$, the stability within $\pm 0.02 \mathrm{~K}$ and the RH in the second DMA reaches an absolute accuracy of $\pm 1.2 \%$ for $98 \%$. More detailed information regarding the HH-TDMA-system is provided by Hennig et al. (2005).

During the HaChi summer campaign, the RH values of the second DMA were set to be $90 \%, 95 \%$ and $98.5 \%$. The dry diameters selected by the first DMA were set to be $50 \mathrm{~nm}$, $100 \mathrm{~nm}, 200 \mathrm{~nm}$ and $250 \mathrm{~nm}$. For calibration, the growth factors of ammonium sulphate particles with $200 \mathrm{~nm}$ dry size at low RH (approximately $22.5 \%$ in this study) and at $90 \%$, 95\% and $98.5 \%$ RH were measured every day. The hygroscopic behaviour of the ammonium sulphate particles is well depicted by the Köhler theory with a parameterized van't Hoff factor as a function of molality (the molality is defined as the amount of constituent divided by the mass of the solvent water, unit: $\mathrm{mol} \mathrm{kg}^{-1}$ ). The parameterization scheme for $0.1<$ molality $<5.5 \mathrm{~mol} \mathrm{~kg}^{-1}$ was taken from Low (1969), while that for $10^{-5}<$ molality $<0.1 \mathrm{~mol} \mathrm{~kg}^{-1}$ was taken from Young and Warren (1992). Since $200 \mathrm{~nm}$ ammonium sulphate particles are unable to take up water at RH lower than the deliquescence point (about 80\%) in the HH-TDMA, the low RH scans were applied to calibrate any possible offset in sizing by the second DMA cf. the first, as well as to determine the TDMA kernel function, which describes the instrument response used in the inversion algorithm (see Gysel et al., 2009). Ammonium sulphate scans at $\mathrm{RH}$ values greater than $85 \%$ are applied to correct the $\mathrm{RH}$ difference between the second DMA and the DPM at high RH range between $90 \%$ and $100 \%$. The flows in the HHTDMA system were checked by a Primary Standard Airflow Calibrator (Gilian Gilibrator) daily during the measurement period.

In the data quality control routine, the temperature and $\mathrm{RH}$ values recorded by the DPM (placed in the second DMA) and two capacitive RH/temperature sensors (placed in the humidity conditioning section) were used to check the temperature and RH stabilities of the system. For a valid mea- surement scan of the humidified aerosol number size spectrum, the mean temperature at the DPM should be within the range between $19.90^{\circ} \mathrm{C}$ and $20.10^{\circ} \mathrm{C}$, with a standard deviation smaller than $0.05^{\circ} \mathrm{C}$. The standard deviation of DPM RH should be smaller than $0.25 \%$. The threshold values for the maximum standard deviations of $\mathrm{RH}$ and temperature in the humidity conditioning section are $0.5 \%$ and $0.05^{\circ} \mathrm{C}$, respectively. Any scans with larger deviations in $\mathrm{RH}$ or temperature than the threshold values have been screened from the data set. Over the whole period of HaChi summer campaign, $11.4 \%$ of the measurement data were excluded using the criteria described above.

\subsubsection{Data analysis and inversion algorithm}

The goals of the H-TDMA measurement and data analysis approach are to obtain the probability distribution function of the growth factor (GF-PDF), hence the mean GF and the number fraction (nf) for different growth factor ranges. In the HH-TDMA-system, the dry particles with specific mobility diameter are selected by the first DMA and the number size distribution of the humidified aerosol particles is determined using the second DMA and CPC. The measured growth factor distributions can be calculated by dividing the size of the humidified particle by the size of the dry particle. However, due to the finite widths of the size increments of selected particles with two DMAs, the measured distribution function (MDF) is a skewed and smoothed integral transform of the actual growth factor probability distribution function (GFPDF, $c(\mathrm{GF})$ ) (Gysel et al., 2009). Therefore, a data inversion procedure is needed to retrieve the GF-PDF from the measured data. Here, the TDMAinv algorithm (Gysel et al., 2009) was applied to invert each scan of the HH-TDMAmeasured number size distribution of humidified aerosol particles into the actual GF-PDF. The TDMAinv algorithm has been successfully applied to ambient H-TDMA data in previous studies (Gysel et al., 2007; Sjogren et al., 2008). In this algorithm, the GF-PDF is assumed to be a piecewise linear function in fixed growth factor intervals and it is normalized to unity $\left(\int c(\mathrm{GF}) d \mathrm{GF}=1\right)$.

To facilitate the comparison of the measurements at different RHs, a hygroscopic parameter $\kappa$ is calculated using the definitions of Petters and Kreidenweis (2007):

$\kappa(\mathrm{GF})=\left(\mathrm{GF}^{3}-1\right) \cdot\left[\frac{1}{S} \exp \left(\frac{4 \sigma_{\mathrm{s} / \mathrm{a}} M_{\mathrm{w}}}{R T \rho_{\mathrm{w}} D_{0} \mathrm{GF}}\right)-1\right]$

where $S$ represents the saturation ratio ( $S$ is the same as the RH at subsaturation regime, e.g., $S=0.9$ while $\mathrm{RH}=90 \%$ ), $\rho_{\mathrm{w}}$ is the density of water, $M_{\mathrm{w}}$ is the molecular weight of water, $\sigma_{\mathrm{s} / \mathrm{a}}$ is the surface tension of the solution/air interface, $R$ is the universal gas constant, $T$ is the temperature, $D_{0}$ is the diameter of dry particle and $D$ is the diameter of the humidified particle, $\mathrm{GF}=D / D_{0}$. In this study, the temperature used in the $\kappa$ calculation is $20^{\circ} \mathrm{C}$, and the surface tension of the solution/air interface $\sigma_{\mathrm{s} / \mathrm{a}}$ is assumed to be the same 
as the surface tension of the pure water/air interface (about $0.0728 \mathrm{~N} \mathrm{~m}^{-1}$ at $20^{\circ} \mathrm{C}$ ).

Moreover, the concept of $\kappa$-PDF (Probability Distribution Function of $\kappa, c(\kappa))$ is introduced in this study, which represents the normalized distribution of $\kappa$. The $\kappa$-PDF is converted from the GF-PDF for each scan. The ensemble mean growth factor is defined as a volume equivalent mean value of the GF-PDF over the whole GF range: $\mathrm{GF}_{\text {mean }}=\left(\int \mathrm{GF}^{3} \cdot c(\mathrm{GF}) d \mathrm{GF}\right)^{1 / 3}$. The volume equivalent mean growth factor represents the equivalent growth factor if the absorbed water was equally distributed among all particles. The mean hygroscopicity parameters $\left(\kappa_{\text {mean }}\right)$ are calculated from $\mathrm{GF}_{\text {mean }}$ using Eq. (1), which are basically equivalent to the mean value (1st-moment) of the $\kappa$-PDF.

Due to a degree of regularity in the complex mixing state of ambient aerosols, different groupings in terms of modes of hygroscopic growth of particles were frequently and repeatedly observed in our field campaigns. Accordingly, we classify the particles into a nearly-hydrophobic $(\mathrm{NH})$ group, a less-hygroscopic (LH) group, and a more-hygroscopic (MH) group. Conventionally, the soluble particle volume fraction $\varepsilon_{\text {AS }}$ (using ammonium sulphate as the reference compound) is used to define the boundaries for different groups of hygroscopic growth (Swietlicki et al., 2008; Svenningsson et al., 1994; Swietlicki et al., 1999; Rissler et al., 2006). In this study, we use the parameter $\kappa$ as an equivalent alternative to establish boundaries for each grouping of hygroscopic growth. The following values of $\kappa$ have been determined to be suitable for most of our data to separate the hygroscopic groups (GF values are for $100 \mathrm{~nm}$ dry size particles at $\mathrm{RH}=90 \%$; these values varies at other size or $\mathrm{RH}$ ):

Nearly - hydrophobic particles (NH) :

$\kappa<=0.10(\mathrm{GF}<=1.21)$;

Less - hygroscopic particles(LH) :

$\kappa=0.10-0.20(\mathrm{GF}=1.21-1.37)$

More - hygroscopic particles (MH) :

$\kappa>0.20(\mathrm{GF}>1.37)$

For each measured spectrum, the HH-TDMA data is presented as the hygroscopic growth factor $\left(\mathrm{GF}_{\mathrm{NH}, \mathrm{LH}, \mathrm{MH}}\right)$ and number fraction $\left(\mathrm{nf}_{\mathrm{NH}, \mathrm{LH}, \mathrm{MH}}\right)$ for each group. The $\mathrm{GF}_{\mathrm{NH}, \mathrm{LH}, \mathrm{MH}}$ values are calculated as the volume equivalent mean of the GF-PDF within the GF boundaries of each group. The corresponding hygroscopicity parameters $\kappa_{\mathrm{NH}, \mathrm{LH}, \mathrm{MH}}$ are determined by the $\mathrm{GF}_{\mathrm{NH}, \mathrm{LH}, \mathrm{MH}}$ using Eq. (1).

The state of mixing of aerosol particles can be derived from the GF-PDF or $\kappa$-PDF of the measurement scans. Each GF-PDF or $\kappa$-PDF represents a hygroscopicity distribution of particles with the same dry size. Since particles with different hygroscopicity generally represent distinct chemical compositions (or mixing ratio of chemical compounds), the bimodal distribution of a GF-PDF or a $\kappa$-PDF generally indicates an external mixture. The size-resolved $\mathrm{CCN}$ activation ratio at given supersaturations can be also derived from the size-resolved $\kappa$-PDF. Recently, an article by Su et al. (2010) gave a detailed description of the hygroscopicity distribution concept, similar to the $\kappa$-PDF used here, for modelling aerosol mixing state with regard to hygroscopic growth and $\mathrm{CCN}$ activation. Sjogren et al. (2008) suggested using the standard deviation $\sigma$ of the inverted GF-PDF $\left(\sigma_{\mathrm{GF}}\right)$ as a measure for the spread of growth factors. In this study, we calculated the standard deviation $\sigma$ of $\kappa$-PDF $\left(\sigma_{\kappa}\right)$ to estimate the spread of $\kappa$, thus represent the state of mixing in terms of hygroscopic growth. Any scan with large $\sigma$ of $\kappa$-PDF value (e.g., $>0.08$ ) indicates that aerosol particles are highly externally mixed, while small $\sigma$ of $\kappa$-PDF value (e.g., <0.08) indicates a state of low degree of external mixing or quasiinternal mixing. In this paper, the standard deviations of GFPDF and $\kappa$-PDF for $\mathrm{NH}$ and $\mathrm{MH}$ modes are also presented.

\subsubsection{Correction of HH-TDMA data to set RHs}

The HH-TDMA instrument was set at 90\%, 95\% and 98.5\% RHs. Over the whole summer campaign, the deviations of actual RH (measured by the DPM and calibrated using the ammonium sulphate particles) from the set value were smaller than $1.5 \%$ for $90 \% \mathrm{RH}$, while for $95 \%$ and $98.5 \%$ $\mathrm{RH}$ the deviations were normally within $\pm 0.5 \%$ from set values. For each measurement, the $\mathrm{GF}_{\text {mean }}$ and $\mathrm{GF}_{\mathrm{NH}, \mathrm{LH}, \mathrm{MH}}$ were corrected using $\kappa$-Köhler model, i.e., the corrected GF values were recalculated at their nominal values using the $\kappa$. For GF-PDF, the RH correction is more complicated. Since the $\kappa$-Köhler model cannot be solved analytically for GF using RH and $\kappa$, the $\gamma$-model (Eq. 4 in Gysel et al., 2009) was chosen to calculate the RH correction for GF-PDF. The $\gamma$ model overcomes the computational difficulty of the $\kappa$-model in correcting GF-PDF, and comparison shows that the correction using the $\gamma$-model yields nearly the same results as the correction using the $\kappa$-Köhler model in this study.

\subsection{Regional meteorological model and aerosol box model}

\subsubsection{The WRF model}

In this study, the Weather Research and Forecast Model (WRF, Skamarock et al., 2005) version 2.2 was used to generate the gridded meteorological fields. The simulation uses two nested domains with one-way nesting at resolutions of $18 \mathrm{~km}$ and $6 \mathrm{~km}$, with $101 \times 101(1800 \mathrm{~km} \times 1800 \mathrm{~km})$ and $250 \times 250(1500 \mathrm{~km} \times 1500 \mathrm{~km})$ grid cells, respectively. There are 27 vertical levels using the eta coordinate in the simulations. The initial and boundary conditions were taken from the Global Forecast System (GFS, NCEP FNL, $1.0 \times 1.0^{\circ}$ ) data at a 6 -h resolution. The Yonsei University 
(YSU) boundary layer scheme (Hong et al., 2006) and the 5-class microphysics scheme (WSM5) were used in the model. The simulated meteorological fields were available from 00:00 on 11 July to 00:00 on 15 August 2009 (UTC) for HaChi summer campaign. To better adapt the boundary conditions provided by NCEP data, the whole campaign was separated into several continuous 3-day short periods for WRF simulations. Each WRF run was initialized 12-h before the corresponding period, and the first 12-h data were used for modelling spin-up followed by the 3-day simulation period. The meteorological fields were output and stored every hour for analysis. In this paper, the simulated boundary layer (PBL) height was applied to initialize the PartMC-MOSAIC model (see Sect. 2.3.2). This high resolution meteorological field is also applied in other studies under HaChi project, such as back trajectory calculation (e.g., Göbel et al., 2011).

\subsubsection{The PartMC-MOSAIC model}

The PartMC-MOSAIC recently developed by Riemer et al. (2009) is a stochastic particle-resolved aerosol box model, which explicitly resolves the composition of individual particles in a given population of different types of aerosol particles. The PartMC model uses a Monte-Carlo approach for simulating the coagulation process stochastically. Particle emissions as well as the dilution with air representative of the lower free tropospheric above the nocturnal boundary layer are also modelled in a stochastic manner. The PartMC was coupled with a new state-of-the-art aerosol chemistry module MOSAIC (Model for Simulating Aerosol Interactions and Chemistry, Zaveri et al., 2008), which simulates the gas and particle phase chemistries, particle phase thermodynamics, and dynamic gas-particle mass transfer in a deterministic manner. The coupled system predicts number, mass and full composition distributions. It treats all globally important aerosol species including sulphate, nitrate, chloride, carbonate, ammonium, sodium, calcium, other inorganic mass, primary organic aerosol (POA), secondary organic aerosol (SOA), and black carbon (BC). The hygroscopicity parameter $\kappa$ for each aerosol particle is assumed to be the average of the $\kappa$ values of the constituent species weighted by their volume fractions. The assignment of individual $\kappa$ values is taken from Riemer et al. (2010), assuming $\kappa=0.65$ for all salts formed from the $\mathrm{NH}_{4}^{+}-\mathrm{SO}_{4}^{2-}-\mathrm{NO}^{3-}$ system, $\kappa=0.1$ for SOA, $\kappa=0.001$ for POA and $\kappa=0$ for BC.

The simulated scenario represents a Lagrangian air parcel over a large megacity region. The simulation period is started at 18:00 h, 6 August and ended at 18:00 h 9 August 2009 . The model was initialized 12-h before the simulation period for model adjustment. The mixing layer height was initialized based on the PBL height simulated by the WRF model and the temperature and water vapour mixing ratio were set based on the measurements. The initial gas phase concentrations and emission rates are the same as the idealized urban plume scenario described by Riemer et al. (2009), which as- sumed varied gas phase emissions throughout 06:00 to 18:00 according to a typical diurnal cycle found in a polluted urban area.

The initial aerosol distribution, which is representative of a regional average particle distribution, is tri-modal with an Aitken mode and two accumulation modes. The modal parameters of this distribution were adjusted to make the simulated aerosol concentration and distribution generally consistent with the observations using a TDMPS (Tandem Differential Mobility Particle Sizer) combined with an APS (Aerodynamic Particle Sizer). The initial aerosol was assumed to consist of $\left(\mathrm{NH}_{4}\right)_{2} \mathrm{SO}_{4}, \mathrm{POA}$ and $\mathrm{BC}$, with mass fractions of about $60 \%, 35 \%$ and $5 \%$, respectively. The composition of each particle was assumed to be identical, i.e., the initial particles were assumed to be internally mixed. The $\kappa$ value of the initial aerosol is about 0.36 . The mass concentration of the initial aerosol was about $40 \mu \mathrm{g} \mathrm{m}^{-3}$, which is higher than that assumed in Riemer et al. (2009), representing the strong regional aerosol pollution in the North China Plain.

In Riemer et al. (2009) and Riemer et al. (2010), a constant particle emission was assumed during the day between 06:00 to $18: 00 \mathrm{~h} \mathrm{LT}$, and all emissions were switched off during the night. Three types of carbonaceous aerosols were considered in the emission: (1) meat cooking (100\% POA), (2) diesel vehicle emissions (30\% POA, 70\% BC), and (3) gasoline vehicle emissions (80\% POA, 20\% BC). This assumption regarding emissions represents an urban plume scenario as described in Riemer et al. (2009). Here, by contrast, we assume a particle emission with the same aerosol types, size distribution and composition as described by Riemer. However, particle emission was not switched off during the night (19:00-07:0 h LT), but changed to $1 / 2$ strength of that during 07:00-19:00 $\mathrm{h} \mathrm{LT}$ instead. The emission rate during 07:0019:00 LT was assumed to be the same as that used in Riemer et al. (2009). The assumption concerning particle emission in our study is basically consistent with the diurnal pattern of black carbon (BC) concentration during HaChi summer campaign observed by the MAAP (Ma et al., 2011), which generally shows a higher value during the nighttime and lower value during daytime. This diurnal variation can be interpreted as a result of the diurnal variation of emission rate combined with the diurnal evolution of mixing height. A continued though lower emission of soot particles at night coupled with the shallow nocturnal mixing layer results in a higher concentration of $\mathrm{BC}$ during the night.

The PartMC-MOSAIC model is applied in this study to simulate the diurnal variations of aerosol hygroscopicity and mixing state for a 3-day scenario (from 6 to 9 August 2009). Comparison between the simulated results and the measurements of the HH-TDMA are presented in Sect. 4. The processes of coagulation, gas and particle phase chemistries and evolution of mixing layer are considered in the model, thus their effects on aerosol hygroscopicity and mixing state can be estimated. 

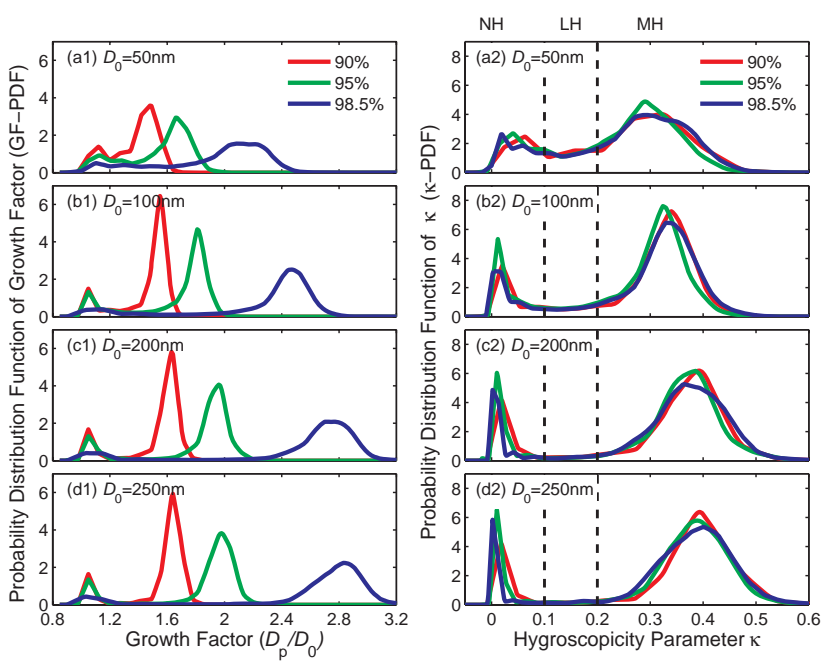

Fig. 2. Averaged probability distribution functions of (a1-d1): growth factor (GF-PDF); (a2-d2): hygroscopicity parameter $\kappa(\kappa$ PDF); dashed lines represent the boundaries of the three defined hygroscopic groups; data were averaged over the whole period of HaChi summer campaign.

\section{Experiment results}

\subsection{Distributions of GF and $\kappa$}

Figure 2 shows the average GF-PDF and the corresponding average $\kappa$-PDF for particles with $50 \mathrm{~nm}, 100 \mathrm{~nm}, 200 \mathrm{~nm}$ and $250 \mathrm{~nm}$ dry diameters. The set values of RH are $90 \%$, $95 \%$ and $98.5 \%$, and the effect of instrumental RH fluctuation on GF-PDF has been corrected (see Sect. 2.2.3). Panels (a1)-(d1) show that the average growth distributions of $50 \mathrm{~nm}, 100 \mathrm{~nm}, 200 \mathrm{~nm}$ and $250 \mathrm{~nm}$ particles are uniformly bimodal. A dominate more-hygroscopic mode and a smaller but distinct, nearly-hydrophobic mode can be observed for each averaged GF-PDF. The peaks of MH modes in GFPDF shift significantly from about $1.4-1.6$ to $2.1-2.8$ (depend on different dry diameters) as the $\mathrm{RH}$ increases from $90 \%$ to $98.5 \%$, whereas the peaks of $\mathrm{NH}$ modes only shift very slightly from about 1.1 to a value of about 1.2; the spread of both modes becomes wider as the RH increases. For the average GF-PDFs with same RH, the peak of MH mode shifts to larger values when the dry diameter increases from $50 \mathrm{~nm}$ to $250 \mathrm{~nm}$, indicating that the hygroscopic particles with larger dry diameters generally have greater growth factors compared to the smaller hygroscopic particles. Panels (a2-d2) show that the measurements at 90\%, 95\% and 98.5\% RH generally achieve similar average distributions of hygroscopicity parameter $\kappa$, indicating that the hygroscopic growths of monodisperse particles measured at different RHs yield consistent results via the $\kappa$-Köhler model. Similar to the GF-PDF, two distinct modes can be seen for each $\kappa$-PDF. The classification of the three different hygroscopic groups described in Sect. 2.2.2 is shown to be appropriate (see Fig.2 a2-d2), since this classification adequately captures the $\mathrm{NH}$ mode and the MH mode for most scans at all RHs and for all dry diameters. The transition regions between the two distinct modes are defined as the LH group, which is overall less important in this study though the LH group has a larger fractional contribution to the PDF at smaller sizes. The average $\kappa$-PDF represents the probability of the occurrence of particles with different hygroscopicity. It means that not only the mixing state but also the temporal variability of hygroscopicity contributes to the spread of $\kappa$-PDF.

It is noted that the $\kappa$ value for the peaks of the $\mathrm{NH}$ mode in the $\kappa$-PDFs decreases slightly as the RH increases. However, considering the inversion resolution $(0.075$ in GF for $90 \% \mathrm{RH}$ and 0.125 for $98.5 \% \mathrm{RH}$ ) and the instrumental uncertainty limits, it is not easy to resolve the detailed hygroscopicity distributions for the nearly-hydrophobic particles, especially at $90 \% \mathrm{RH}$. The slight shifts of $\mathrm{NH}$ mode in $\kappa$ PDFs do not necessarily indicate that the hygroscopicity of the NH group particles has a RH-dependent behaviour. As the RH increases from $90 \%$ to $98.5 \%$, the peak of NH in GF$\mathrm{PDF}$ remains at $\mathrm{GF}=1.1$, but the spread becomes wider at the same time. We also calculated the number fractions of particles with $\mathrm{GF}<1.2$, and the results show that these values decrease significantly as the $\mathrm{RH}$ increase, as presented in Table 1. Taking particles with $100 \mathrm{~nm}$ dry size as an example, the number fractions of $\mathrm{GF}<1.2$ at $90 \%, 95 \%$ and $98.5 \%$ are $0.16 \pm 0.10,0.14 \pm 0.09$ and $0.09 \pm 0.08$, respectively. By contrast, the number fraction of particles with $\kappa<0.1$ (NH group) at three RHs are $0.16 \pm 0.10,0.18 \pm 0.11$ and $0.15 \pm 0.11$. This result indicates that some particles in the $\mathrm{NH}$ group are internally mixed with small amounts of soluble materials (e.g., sulphate, nitrate, etc), or SOA with some sparingly soluble materials; thus, an observable growth behaviour appears at very high RH (>95\%). This slight change in hygroscopic growth behaviour cannot be resolved without taking advantage of the high RH hygroscopic measurement.

The statistics of the HH-TDMA measurements are summarized in Table 1. The particles are classified into the different hygroscopic groups, as described in Sect. 2.2.2. The mean GF, mean $\kappa$, mean nf, spread of GF and $\kappa$ for the NH and $\mathrm{MH}$ groups for the whole $\mathrm{HaChi}$ summer campaign are presented. These parameters, calculated as ensemble mean for all groups, are presented as well. The diameters of $\mathrm{MH}$ particles grow significantly at RH ranges from $90 \%$ to $98.5 \%$. Taking particles with $100 \mathrm{~nm}$ dry size as an example, the mean GF for the MH group at $90 \%, 95 \%$ and $98.5 \mathrm{RH}$ are $1.54,1.81$ and 2.45, respectively; whereas the mean GF for $\mathrm{NH}$ group particles increases slightly from 1.08 at $90 \% \mathrm{RH}$ to 1.24 at $98.5 \% \mathrm{RH}$. No significant variations of mean $\kappa$ or nf were observed at different RHs. Both mean GF and mean $\kappa$ for all groups and for $\mathrm{MH}$ groups increase as a function of particle dry diameter. For NH group particles, the mean $\kappa$ decreases from about 0.05 for $50 \mathrm{~nm}$ particles to about 0.02 for $250 \mathrm{~nm}$ particles. 
Table 1. Summary of the HH-TDMA measurements of hygroscopic growth at $90 \%, 95 \%$ and $98.5 \%$ RH during HaChi summer campaign (mean value \pm 1 standard deviation).

\begin{tabular}{|c|c|c|c|c|c|c|c|c|c|c|c|c|}
\hline \multirow{2}{*}{$\begin{array}{l}\text { Dry diameter (nm) } \\
\mathrm{RH}(\%)\end{array}$} & \multicolumn{3}{|c|}{50} & \multicolumn{3}{|c|}{100} & \multicolumn{3}{|c|}{200} & \multicolumn{3}{|c|}{250} \\
\hline & 90 & 95 & 98.5 & 90 & 95 & 98.5 & 90 & 95 & 98.5 & 90 & 95 & 98.5 \\
\hline Number of scans & 226 & 218 & 205 & 758 & 320 & 416 & 244 & 221 & 218 & 168 & 156 & 151 \\
\hline inversion resolution $\Delta \mathrm{GF}$ & 0.075 & 0.075 & 0.10 & 0.075 & 0.075 & 0.125 & 0.075 & 0.075 & 0.125 & 0.075 & 0.075 & 0.125 \\
\hline Number fraction of $\mathrm{GF}<1.2$ group & $0.22 \pm 0.14$ & $0.13 \pm 0.11$ & $0.07 \pm 0.0 .08$ & $0.16 \pm 0.10$ & $0.14 \pm 0.09$ & $0.09 \pm 0.08$ & $0.16 \pm 0.09$ & $0.14 \pm 0.09$ & $0.10 \pm 0.08$ & $0.15 \pm 0.10$ & $0.13 \pm 0.09$ & $0.09 \pm 0.09$ \\
\hline \multicolumn{13}{|l|}{ Nearly-hydrophobic group, $\mathrm{NH}$} \\
\hline Number fraction & $0.18 \pm 0.12$ & $0.20 \pm 0.13$ & $0.17 \pm 0.13$ & $0.16 \pm 0.10$ & $0.18 \pm 0.11$ & $0.15 \pm 0.11$ & $0.16 \pm 0.09$ & $0.16 \pm 0.10$ & $0.12 \pm 0.10$ & $0.15 \pm 0.10$ & $0.14 \pm 0.10$ & $0.11 \pm 0.10$ \\
\hline Mean GF \pm std (when present) & $1.10 \pm 0.03$ & $1.16 \pm 0.04$ & $1.25 \pm 0.08$ & $1.08 \pm 0.02$ & $1.13 \pm 0.06$ & $1.24 \pm 0.13$ & $1.07 \pm 0.02$ & $1.10 \pm 0.05$ & $1.17 \pm 0.14$ & $1.06 \pm 0.02$ & $1.09 \pm 0.04$ & $1.15 \pm 0.15$ \\
\hline Mean spread $\sigma$ of GF & $0.04 \pm 0.01$ & $0.07 \pm 0.02$ & $0.11 \pm 0.03$ & $0.05 \pm 0.01$ & $0.07 \pm 0.02$ & $0.14 \pm 0.06$ & $0.04 \pm 0.01$ & $0.06 \pm 0.03$ & $0.12 \pm 0.07$ & $0.04 \pm 0.01$ & $0.05 \pm 0.02$ & $0.10 \pm 0.06$ \\
\hline Mean $\kappa \pm$ std & $0.054 \pm 0.014$ & $0.051 \pm 0.013$ & $0.049 \pm 0.017$ & $0.034 \pm 0.011$ & $0.032 \pm 0.016$ & $0.031 \pm 0.019$ & $0.028 \pm 0.010$ & $0.021 \pm 0.012$ & $0.016 \pm 0.016$ & $0.025 \pm 0.007$ & $0.018 \pm 0.010$ & $0.013 \pm 0.017$ \\
\hline Mean spread $\sigma$ of $\kappa$ & $0.023 \pm 0.005$ & $0.024 \pm 0.006$ & $0.023 \pm 0.007$ & $0.023 \pm 0.006$ & $0.022 \pm 0.008$ & $0.021 \pm 0.009$ & $0.018 \pm 0.005$ & $0.015 \pm 0.007$ & $0.013 \pm 0.009$ & $0.016 \pm 0.005$ & $0.012 \pm 0.007$ & $0.010 \pm 0.007$ \\
\hline \multicolumn{13}{|l|}{ More-hygroscopic group, MH } \\
\hline Number fraction & $0.68 \pm 0.18$ & $0.66 \pm 0.18$ & $0.69 \pm 0.17$ & $0.78 \pm 0.12$ & $0.75 \pm 0.13$ & $0.79 \pm 0.14$ & $0.81 \pm 0.11$ & $0.82 \pm 0.12$ & $0.85 \pm 0.13$ & $0.84 \pm 0.12$ & $0.84 \pm 0.12$ & $0.87 \pm 0.11$ \\
\hline Mean $\mathrm{GF} \pm$ std & $1.46 \pm 0.05$ & $1.68 \pm 0.06$ & $2.13 \pm 0.09$ & $1.54 \pm 0.02$ & $1.81 \pm 0.04$ & $2.45 \pm 0.07$ & $1.61 \pm 0.04$ & $1.94 \pm 0.05$ & $2.74 \pm 0.09$ & $1.63 \pm 0.04$ & $1.98 \pm 0.05$ & $2.81 \pm 0.09$ \\
\hline Mean spread $\sigma$ of GF & $0.051 \pm 0.013$ & $0.065 \pm 0.016$ & $0.117 \pm 0.026$ & $0.055 \pm 0.011$ & $0.069 \pm 0.012$ & $0.125 \pm 0.023$ & $0.061 \pm 0.010$ & $0.082 \pm 0.013$ & $0.142 \pm 0.019$ & $0.060 \pm 0.011$ & $0.081 \pm 0.013$ & $0.140 \pm 0.018$ \\
\hline Mean $\kappa \pm$ std & $0.31 \pm 0.04$ & $0.30 \pm 0.04$ & $0.31 \pm 0.04$ & $0.33 \pm 0.02$ & $0.32 \pm 0.02$ & $0.33 \pm 0.03$ & $0.38 \pm 0.03$ & $0.37 \pm 0.03$ & $0.38 \pm 0.04$ & $0.39 \pm 0.03$ & $0.39 \pm 0.03$ & $0.39 \pm 0.04$ \\
\hline Mean spread $\sigma$ of $\kappa$ & $0.045 \pm 0.012$ & $0.041 \pm 0.011$ & $0.048 \pm 0.011$ & $0.045 \pm 0.009$ & $0.042 \pm 0.008$ & $0.047 \pm 0.009$ & $0.054 \pm 0.009$ & $0.053 \pm 0.009$ & $0.057 \pm 0.009$ & $0.054 \pm 0.010$ & $0.054 \pm 0.009$ & $0.058 \pm 0.009$ \\
\hline \multicolumn{13}{|l|}{ Ensemble mean of all groups } \\
\hline Mean $\mathrm{GF} \pm$ std & $1.39 \pm 0.07$ & $1.57 \pm 0.10$ & $1.97 \pm 0.15$ & $1.48 \pm 0.05$ & $1.70 \pm 0.08$ & $2.31 \pm 0.12$ & $1.54 \pm 0.06$ & $1.84 \pm 0.09$ & $2.61 \pm 0.14$ & $1.57 \pm 0.06$ & $1.89 \pm 0.08$ & $2.70 \pm 0.13$ \\
\hline Mean spread $\sigma$ of $\mathrm{GF}$ & $0.14 \pm 0.04$ & $0.20 \pm 0.06$ & $0.32 \pm 0.11$ & $0.17 \pm 0.05$ & $0.25 \pm 0.08$ & $0.42 \pm 0.17$ & $0.20 \pm 0.05$ & $0.29 \pm 0.08$ & $0.47 \pm 0.20$ & $0.20 \pm 0.06$ & $0.29 \pm 0.10$ & $0.45 \pm 0.22$ \\
\hline Mean $\kappa \pm$ std & $0.25 \pm 0.06$ & $0.24 \pm 0.06$ & $0.25 \pm 0.06$ & $0.28 \pm 0.04$ & $0.26 \pm 0.04$ & $0.28 \pm 0.04$ & $0.32 \pm 0.04$ & $0.31 \pm 0.05$ & $0.33 \pm 0.05$ & $0.34 \pm 0.05$ & $0.33 \pm 0.05$ & $0.35 \pm 0.05$ \\
\hline Mean spread $\sigma$ of $\kappa$ & $0.10 \pm 0.03$ & $0.10 \pm 0.03$ & $0.10 \pm 0.03$ & $0.11 \pm 0.03$ & $0.11 \pm 0.03$ & $0.11 \pm 0.04$ & $0.13 \pm 0.03$ & $0.13 \pm 0.03$ & $0.12 \pm 0.04$ & $0.13 \pm 0.04$ & $0.13 \pm 0.04$ & $0.12 \pm 0.05$ \\
\hline
\end{tabular}

\subsection{Time series, meteorology and diurnal variation}

The meteorological parameters, e.g., wind direction (WD), wind speed (WS), temperature $(T)$ and relative humidity (RH) were continuously measured at Wuqing meteorological station by instruments which were beside the containers with the aerosol instruments. The time series of meteorological parameters are presented in Fig. 3, panel ( $a$ and b). The ambient $T$ and RH both show pronounced diurnal variation with high temperature and low RH during the day and the opposite during the night. For particles with $100 \mathrm{~nm}$ dry diameter, the time series of hygroscopicity parameters for all groups $\left(\kappa_{\text {mean }}\right), \mathrm{MH}$ group $\left(\kappa_{\mathrm{MH}}\right)$ and $\mathrm{NH}$ group $\left(\kappa_{\mathrm{NH}}\right)$ are shown in panels (c-e), and the number fraction of $\mathrm{MH}$ group $\left(\mathrm{nf}_{\mathrm{MH}}\right)$ and $\mathrm{NH}$ group $\left(\mathrm{nf}_{\mathrm{NH}}\right)$ are illustrated in panels ( $\mathrm{f}-$ $\mathrm{g}$ ), respectively. Panels $(\mathrm{c}-\mathrm{g})$ demonstrate that the hygroscopicity parameters and number fractions measured at $90 \%$, 95\% and $98.5 \% \mathrm{RH}$ generally yield consistent results, indicating that the RH-dependence of aerosol hygroscopicity $\kappa$ is not important in the RH range between $90 \%-98.5 \%$ in this study. Figure 4 depicts the results of autocorrelation analysis for meteorological parameters (panel a) and for $\kappa_{\text {mean }}$, $\kappa_{\mathrm{MH}}$ and $\mathrm{nf}_{\mathrm{NH}}$ of $100 \mathrm{~nm}$ dry diameter particles measured at three RHs (panel b). The correlation coefficient of ambient $T$ and ambient $\mathrm{RH}$ show sinusoidal variations, with high values of $0.5-0.6$ when $\Delta t=24,48$ and $72 \mathrm{~h}$, demonstrating the pronounced diurnal variations of these variables. These results are consistent with those depicted in Fig. 3a, b. Similarly, autocorrelation analysis shows that the diurnal variation of $\mathrm{nf}_{\mathrm{NH}}$ is very pronounced, and that of $\kappa_{\text {mean }}$ is relatively weaker, but it is still significant. The diurnal variation for the $\kappa_{\mathrm{MH}}$ was found to be less obvious (see Fig. 4b). Similar analyses were also done for $\mathrm{nf}_{\mathrm{MH}}$ and $\kappa_{\mathrm{NH}}$ (not shown in the figure), and both show significant diurnal variations. The
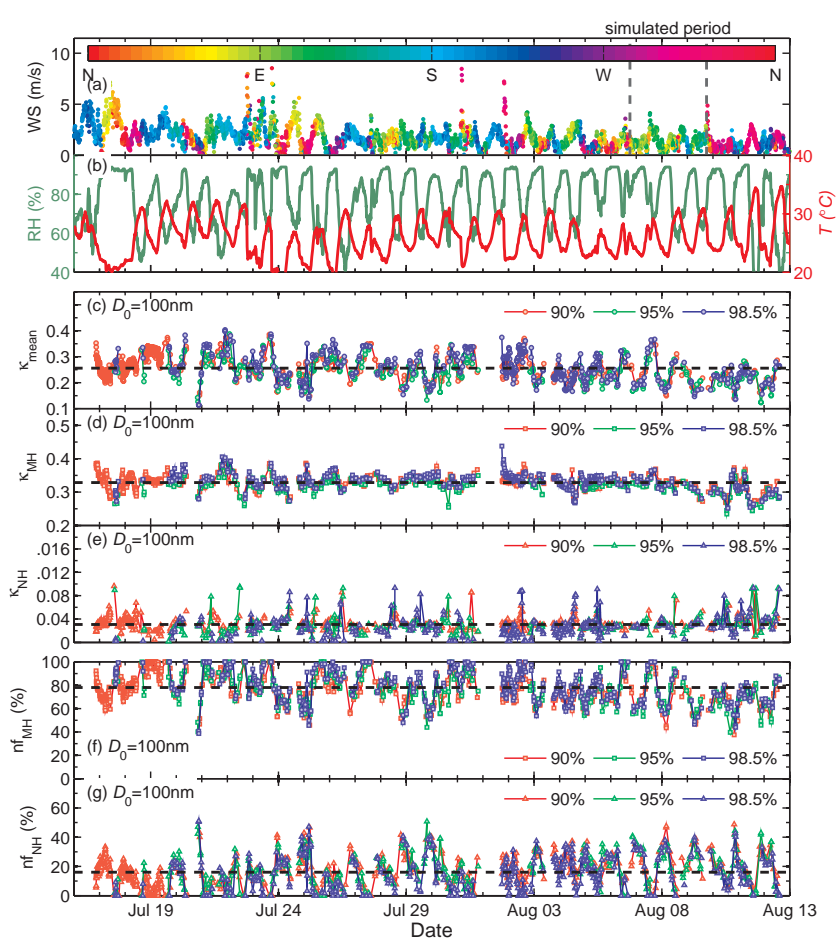

Fig. 3. Time series of meteorological parameters and hygroscopic properties of $100 \mathrm{~nm}$ particles in the HaChi summer campaign. (a): wind speed and wind direction; (b) temperature $(T)$ and relative humidity (RH); (c): mean $\kappa$ (averaged over both modes, $100 \mathrm{~nm}$ dry diameter); (d): $\kappa$ of more-hygroscopic group particles; (e): $\kappa$ of nearly-hydrophobic mode particles; (f): number fraction of more-hygroscopic group particles; (g): number fraction of nearlyhydrophobic group. The dashed lines represent the average value of each parameter. 


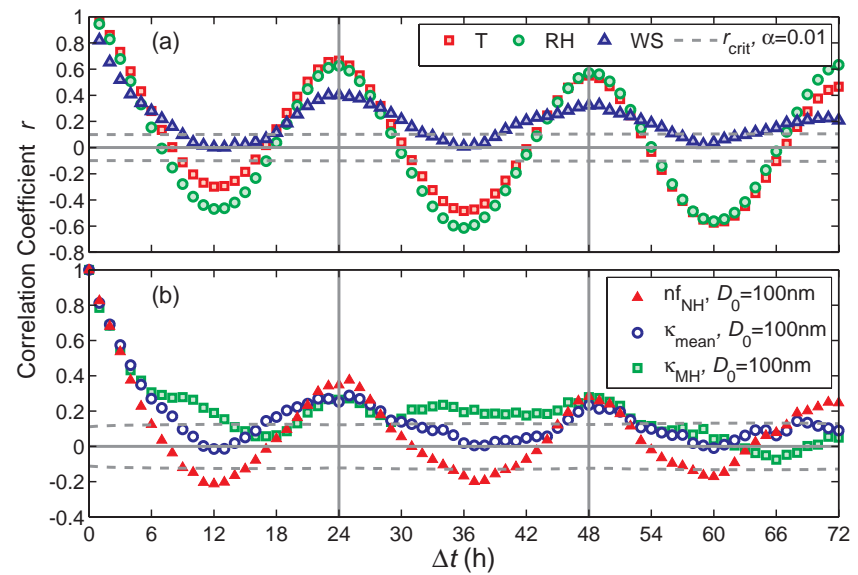

Fig. 4. Autocorrelation analysis of meteorological parameters and hygroscopic properties of $100 \mathrm{~nm}$ particles. (a) temperature $(T)$, relative humidity $(\mathrm{RH})$ and wind speed (WS); (b) number fraction of nearly-hydrophobic group $\left(\mathrm{nf}_{\mathrm{NH}}\right)$, mean $\kappa(\kappa$ mean $)$ and $\kappa$ of more hygroscopic group $\left(\kappa_{\mathrm{MH}}\right)$. The dashed lines show the significance level of 0.01 .

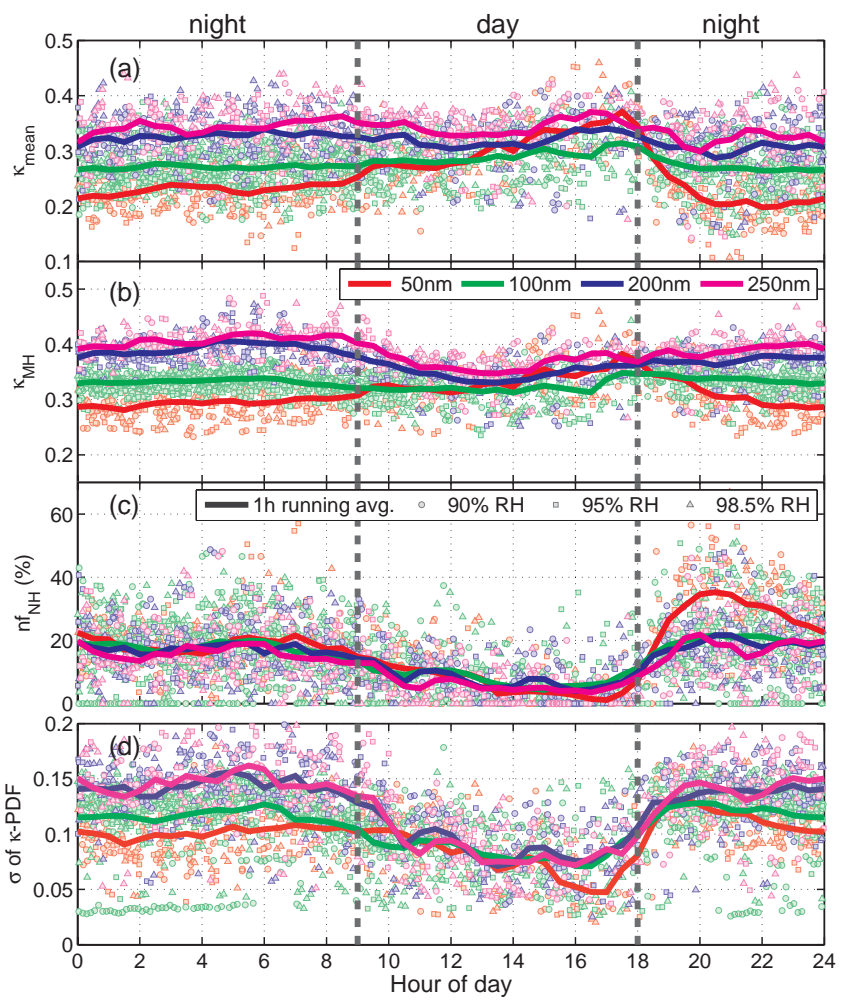

Fig. 5. Diurnal variations of aerosol hygroscopic properties; (a) mean $\kappa$ of all groups; (b) $\kappa$ of more-hygroscopic group; (c) the number fraction of nearly-hydrophobic group; (d) the spread of $\kappa$ PDF.

time series and autocorrelation analysis indicate that the fraction of $\mathrm{NH}$ particles, e.g., freshly emitted soot, varies greatly during a day while the hygroscopicity of $\mathrm{MH}$ group parti- cles is relatively stable during the measurement period. The variation of hygroscopicity of all groups is largely due to the diurnal variation of number fraction of $\mathrm{NH}$ group particles.

The average diurnal variations of $\kappa_{\text {mean }}, \kappa_{\mathrm{MH}}$ and $\mathrm{nf}_{\mathrm{NH}}$ of $50 \mathrm{~nm}, 100 \mathrm{~nm}, 200 \mathrm{~nm}$ and $250 \mathrm{~nm}$ dry diameters during HaChi summer campaign are presented in Fig. 5a-c. These parameters generally show different characteristics between daytime and nighttime measurements. An apparent feature of the diurnal pattern is that the $\mathrm{nf}_{\mathrm{NH}}$ of all dry diameters changes significantly with time of a day (see Fig. 5c). The average $\mathrm{nf}_{\mathrm{NH}}$ between 18:00 to 09:00 (nighttime) is about $20 \%$, while between 09:00 to 18:00 (day-time) it is about $8 \%$. A significant decrease and rapid increase of $\mathrm{nf}_{\mathrm{NH}}$ were often observed at 08:00 to 10:00 and at around 18:00, respectively. Figure $5 \mathrm{a}$ shows that the average $\kappa_{\text {mean }}$ for $100 \mathrm{~nm}, 200 \mathrm{~nm}$ and $250 \mathrm{~nm}$ particles increases slightly during the day, while the average $\kappa_{\text {mean }}$ for $50 \mathrm{~nm}$ increases significantly, representing that the hygroscopicity of aerosol particles with 50 to $250 \mathrm{~nm}$ dry diameters is enhanced during the day due to the decrease of the fraction of $\mathrm{NH}$ particles. The differences of $\kappa_{\mathrm{MH}}$ for particles with different dry diameters are smaller during the day than during the night (see Fig. 5b), indicating that during the day the chemical composition is more evenly distributed across dry diameter. Figure $5 d$ indicates that the spread of $\kappa$-PDF, which basically represents the dispersion of chemical composition (in terms of the hygroscopic growth) among particles with the same dry diameters, decreases during the day.

The diurnal patterns of the parameters mentioned above reflect the variation of aerosol mixing states. The high number fraction of $\mathrm{NH}$ particles during the night indicates that the freshly emitted hydrophobic particles, (e.g., fresh soot or primary organic aerosol, see Petters et al., 2006 and Zhang et al., 2008) have accumulated in the surface layer, apparently externally mixed with the hygroscopic particles. During the day, the fraction of $\mathrm{NH}$ mode, $\mathrm{nf}_{\mathrm{NH}}$ is smaller (see Fig. 5c), indicating that aged aerosol was dominant in the atmosphere near the surface. Figure 5a, b, and d show clearly that differences in hygroscopicity, $\kappa$, among particles are less apparent during the day, indicating that the extent of external mixing is lower in the daytime compared to that at night. Similar results regarding the diurnal variations of aerosol hygroscopicity and mixing state were reported several previous studies (e.g. Moffet and Prather, 2009; Lance, 2007; Rose et al., 2011). These measurements were also made in megacity areas (Mexico City, Mexico, for Moffet and Prather, 2009 and Lance, 2007; Guangzhou, China, for Rose et al., 2011).

\subsection{Hygroscopic growth at high humidity}

Figure 6a1-d1 show the hygroscopic growths of aerosol particles with $50 \mathrm{~nm}, 100 \mathrm{~nm}, 200 \mathrm{~nm}$ and $250 \mathrm{~nm}$ dry diameters, respectively. The squares and crosses represent the average growth factors of $\mathrm{MH}$ group and $\mathrm{NH}$ group measured by 
the HH-TDMA, respectively (corrected to the nominal RHs), and the error bars denote the standard deviations; red and blue colours represent measurements during the day (09:0018:00 LT) and during the night (18:00-09:00 LT), respectively. The fitted curves are $\kappa$-Köhler curves using the averaged $\kappa$ measured at all RHs. The reference curves (green solid curves) are calculated Köhler curves for ammonium sulphate particles, using the scheme from Low (1969) and Young and Warren (1992). It can be seen that the growth curves can be well described with the single-parameter $(\kappa)$ Köhler model given in Eq. (1). Over time, remarkably consistent hygroscopic growths were observed for hygroscopic group particles with all dry diameters. Compared to the hygroscopic growth factors of pure ammonium sulphate particles, those of MH group particles with $50 \mathrm{~nm}$ and $100 \mathrm{~nm}$ dry diameters reveal relatively lower values (see Fig. 6a1 and b1), indicating that these particles are quasi-internal mixtures of both inorganic compounds (e.g., sulphate, nitrate and sodium chloride, with strong hygroscopicity) with organic compounds (normally slightly hygroscopic or hydrophobic), or an insoluble core (e.g., soot or dust) with inorganic coating. By comparison, MH group particles with $200 \mathrm{~nm}$ and $250 \mathrm{~nm}$ dry diameters demonstrate larger hygroscopic growth factors (see Fig. 6c1 and d1). For large particle size, growth factors are as high as 1.6 at $90 \%$ and about 2.8 at 98.5\% RH (for $250 \mathrm{~nm}$ particles, nighttime measurements). These pronounced growths in diameter imply dramatic enhancement in aerosol scattering with a correspondingly large change in other aerosol optical properties at high RHs. The hygroscopic growths of $200 \mathrm{~nm}$ and $250 \mathrm{~nm}$ MH group particles are only slightly lower than those of the pure ammonium sulphate particles, indicating that these particles contain large fractions of inorganic compounds. The error bars of $\mathrm{GF}_{\mathrm{MH}}$ measured by the HH-TDMA are generally small, indicating that the temporal variations of $\mathrm{GF}_{\mathrm{MH}}$ at the same RH (due to the variations of hygroscopicity) are less significant than the variations of $\mathrm{GF}_{\mathrm{MH}}$ due to the change of $\mathrm{RH}$. The HHTDMA measurements show that the hygroscopicity factor $\kappa$ of $\mathrm{MH}$ group particles during the day is about $9 \%$ lower than that during the night.

The hygroscopic growths for the NH group particles at high $\mathrm{RH}$ are much weaker compared to those for the $\mathrm{MH}$ group particles. The $\mathrm{GF}_{\mathrm{NH}}$ values are generally lower than $1.2-1.3$ during the night at $\mathrm{RH}<98.5 \%$. During the day, the average $\mathrm{GF}_{\mathrm{NH}}$ values are slightly higher and the standard deviations (which show the temporal variations) are larger than those during the night.

Figure $6 \mathrm{a} 2-\mathrm{d} 2$ shows the average number fractions of three hygroscopic groups during daytime and nighttime, respectively. No significant variations of $\mathrm{nf}$ values were observed at three different RHs for either daytime or nighttime measurements. The $\mathrm{nf}_{\mathrm{NH}}$ values measured at nighttime were significant higher than that during daytime, while the $\mathrm{nf}_{\mathrm{MH}}$ were higher during the day. The number fractions of the transition group, $\mathrm{nf}_{\mathrm{LH}}$, were larger at smaller sizes $(\sim 14 \%$
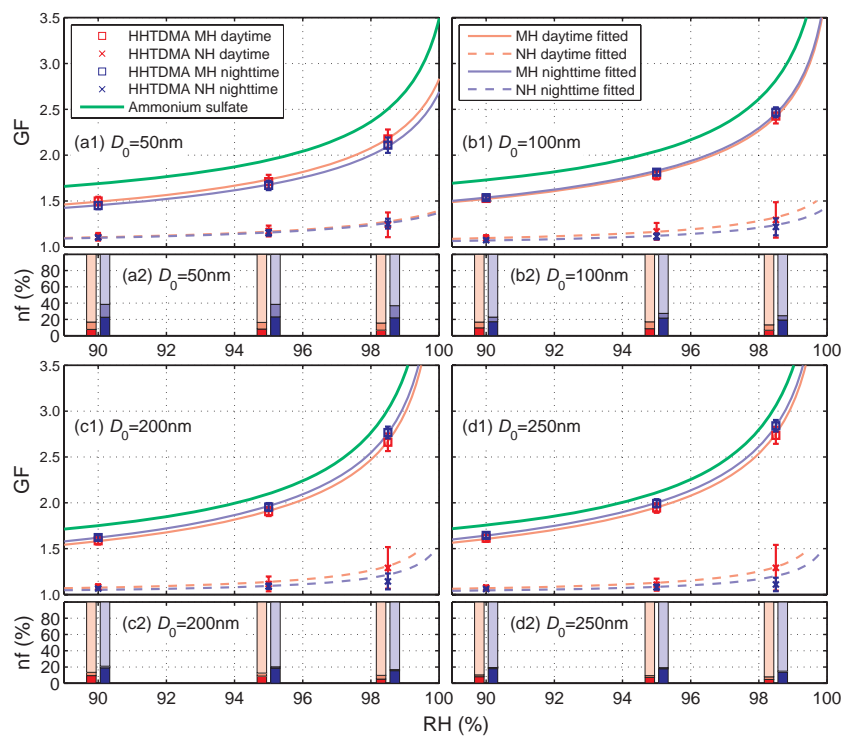

Fig. 6. (a1-d1) the hygroscopic growth of aerosol particles with different dry diameters of $50 \mathrm{~nm}, 100 \mathrm{~nm}, 200 \mathrm{~nm}$ and $250 \mathrm{~nm}$, respectively. The growth factors (GF) of nearly-hydrophobic (NH) group and more-hygroscopic $(\mathrm{MH})$ group are the mean values of the measured GFs corrected to their set RHs (90\%, 95\% and 98.5\%); the error bars represent $\pm 1 \mathrm{~s}$. d.; the blue and red lines are fitted $\kappa$-Köhler curves using the mean $\kappa$ measured by the HH-TDMA; the green lines are the hygroscopic growth of ammonium sulphate particles calculated following Low (1969) and Young and Warren (1992). (a2-d2) the mean number fractions of nearly-hydrophobic (NH) group, less-hygroscopic (LH) group and more-hygroscopic $(\mathrm{MH})$ group particles (from dark colour to light colour) with $50 \mathrm{~nm}$, $100 \mathrm{~nm}, 200 \mathrm{~nm}$ and $250 \mathrm{~nm}$ dry diameters.

at $50 \mathrm{~nm}$ and $\sim 6 \%$ at $100 \mathrm{~nm}$ ) but negligible for larger sizes $(<3 \%$ at $200 \mathrm{~nm}$ and $25 \mathrm{~nm})$.

\subsection{Parameterization of HH-TDMA data}

To further facilitate the use of HH-TDMA data, $\kappa$ can be parameterized as a function of dry diameter, $D_{0}$, using the equation (Rissler et al., 2006):

$\kappa\left(D_{0}\right)=B \log \left(D_{0}\right)+C D_{0}+D$

where $B, C$ and $D$ are fitted parameters. In Rissler et al. (2006), an equation similar to Eq. (2) as presented here was used to parameterize the size-dependent variation of $A$, where $A$ is identical to $\kappa$ in principle, if the Kelvin term is neglected. Similarly, the $\mathrm{nf}$ is also parameterized as a function of $D_{0}$ using the same equation as Eq. (2), by replacing $\kappa\left(D_{0}\right)$ with $\operatorname{nf}\left(D_{0}\right)$. Examples for the parameterizations are presented in Fig. 7. The value of $\kappa$ for the MH group particles measured during the night increases significantly with particle dry diameter, suggesting an increasing fraction of soluble components. However, the $\kappa_{\mathrm{MH}}$ is significantly less than the $\kappa$ of pure ammonium sulphate particles (green lines). During 


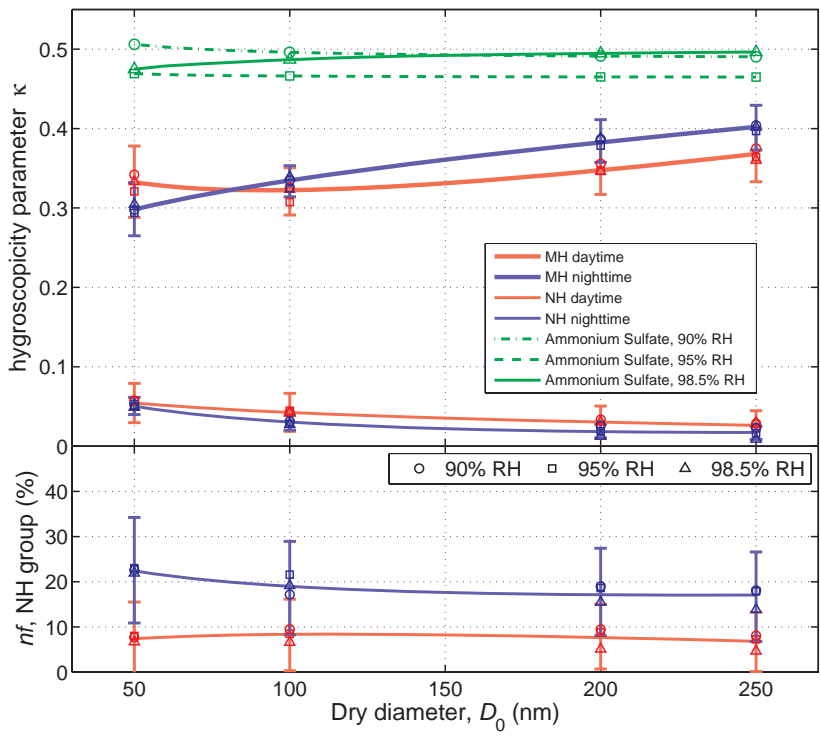

Fig. 7. Parameterization of $\kappa$ and nf. The upper panel shows the parameterizations of $\kappa$ as functions of dry diameter for morehygroscopic group and nearly-hydrophobic group particles during the day and during the night, respectively; the lower panel shows the parameterizations of the number fractions of nearly-hydrophobic group particles.

the day, the $\kappa_{\mathrm{MH}}$ increases slightly for diameters greater than $100 \mathrm{~nm}$, indicating that the variation of soluble fraction with diameter is less pronounced than that during the night. For $50 \mathrm{~nm} \mathrm{MH}$ particles, daytime measurements show stronger hygroscopicity, which suggest that the Aitken mode particles may have different sources during the day from that during the night. In contrast to the $\mathrm{MH}$ group described above, the $\kappa$ of NH group particles decreases slightly as a function a dry diameter, for both day and night measurements.

In this study, $\kappa$ and $\mathrm{nf}$ for $\mathrm{MH}$ group, $\mathrm{NH}$ group and ensemble mean for all groups during the day, during the night and during the whole period have been fitted empirically as described above. The values of the parameters in Eq. (2) are summarized in Table 2. The parameterized GFs can be derived by solving Eq. (1) using $\kappa$ values calculated from Eq. (2) combined with parameters in Table 2. A lookup table was made for GF values as a function of dry diameter and RH. The result is illustrated in Fig. 8 panels $(\mathrm{a}-\mathrm{c})$, which show the parameterized mean GF of all groups for day-time, night-time and whole period measurements, respectively. GF values which are represented by the colour of the contour lines can be read directly from the figure. Similar lookup tables or contour figures can also be made for each hygroscopic group separately, using the data in Table 2. To validate our parameterization for GF, Fig. 8d presents a comparison between the parameterized GF and the measured GF. The comparison result shows that, in most cases our parameterizations adequately capture the variations of GF and $\mathrm{nf}$
Table 2. Summary of fitting parameters for the parameterization of $\kappa$ and nf; see Eq. (2) and Sect. 3.4 for description.

\begin{tabular}{lrrr}
\hline \multicolumn{1}{c}{ B } & C & D \\
\hline Summer daytime scans & & & \\
\hline$\kappa$ more-hygroscopic group & -0.150 & 0.000703 & 0.553 \\
$\kappa$ nearly-hydrophobic group & -0.0391 & $-4.12 \times 10^{-6}$ & 0.121 \\
$\kappa$ all groups & -0.172 & 0.000807 & 0.553 \\
nf more-hygroscopic group & -0.0930 & 0.000664 & 0.963 \\
nf nearly-hydrophobic group & 0.0886 & -0.000337 & -0.0596 \\
\hline Summer nighttime scans & & & \\
\hline$\kappa$ more-hygroscopic group & 0.0837 & 0.000228 & 0.144 \\
$\kappa$ nearly-hydrophobic group & -0.0926 & 0.000158 & 0.200 \\
$\kappa$ all groups & 0.136 & $8.00 \times 10^{-5}$ & -0.0101 \\
nf more-hygroscopic group & 0.644 & -0.00129 & -0.408 \\
nf nearly-hydrophobic group & -0.166 & 0.000313 & 0.491 \\
\hline summer average & & & \\
\hline$\kappa$ more-hygroscopic group & 0.0285 & 0.000320 & 0.243 \\
$\kappa$ nearly-hydrophobic group & -0.0812 & 0.000126 & 0.183 \\
$\kappa$ all groups & 0.0533 & 0.000279 & 0.141 \\
nf more-hygroscopic group & 0.431 & -0.000682 & -0.0196 \\
nf nearly-hydrophobic group & -0.0770 & $3.09 \times 10^{-5}$ & 0.314 \\
\hline & & & \\
\hline
\end{tabular}

as functions of dry diameter and RH (90\%-98.5\%). For the GF of NH group during the night at $98.5 \% \mathrm{RH}$, the parameterized GF deviates slightly from the measured values. Since the parameterizations are based on the measured size range $50-250 \mathrm{~nm}$, we do not recommend extrapolating Eq. (2) to particles larger than $250 \mathrm{~nm}$ or smaller than $50 \mathrm{~nm}$. It is worth to note that Meier et al. (2009) and Eichler et al. (2008) observed a decreasing trend in GF for particles larger than $300 \mathrm{~nm}$, based on the measurements conducted in Beijing (North China Plain) and Xinken (Pearl River Delta in SouthEastern China), respectively. The decrease in hygroscopicity for large particles is because of higher contents of mineral dust.

\section{Diurnal variations of aerosol hygroscopicity and mixing state: a case study}

\subsection{Description of meteorological situation}

To better understand the chemical and meteorological processes dominating the diurnal variation of aerosol hygroscopicity and mixing state, a state-of-the-art, stochastic, particleresolved aerosol box model PartMC-MOSAIC was applied to simulate the aerosol hygroscopicity and mixing state (see Sect. 2.3.2 for the description of the model). A 3-day period from 6 August 18:00 LT to 9 August 2009, 18:00 LT was selected for the simulations. Influenced by the slow-moving typhoon "Morakot" near Taiwan about $2000 \mathrm{~km}$ south from the 

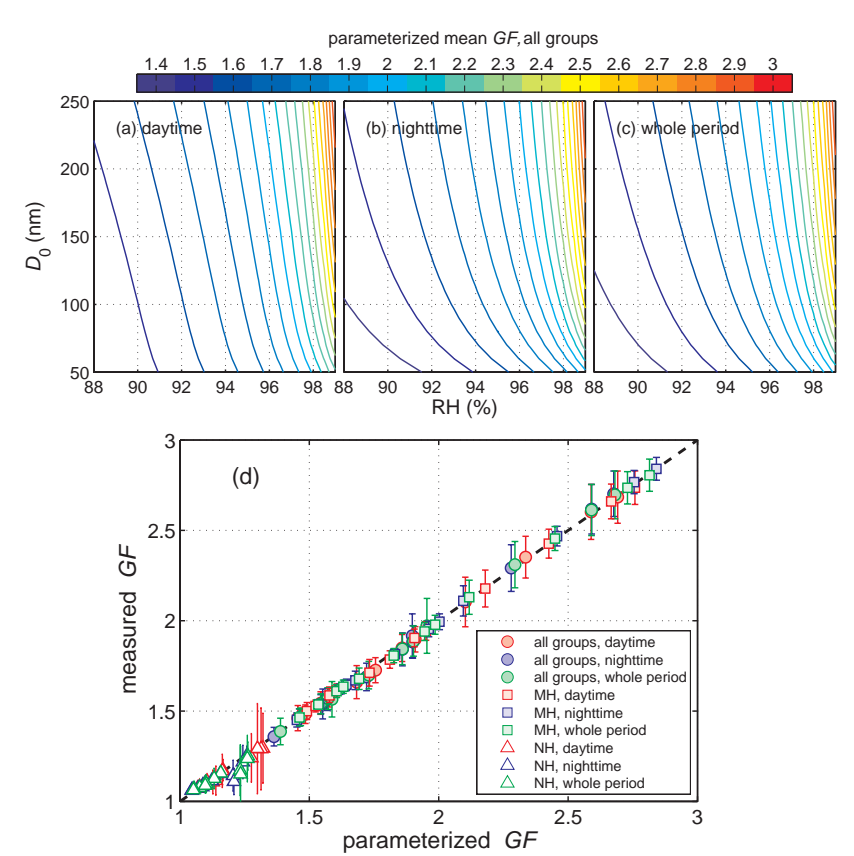

Fig. 8. Contours show the parameterized mean growth factors of all groups during (a) daytime; (b) nighttime; (c) whole period of HaChi summer campaign. (d) Comparison between measured and parameterized growth factors; the error bars represent the one standard deviation of the measurements during the summer campaign period; the dashed line shows the 1:1 line.

site, the synoptic situation of Wuqing during this period was relatively constant, with $<3 \mathrm{~m} \mathrm{~s}^{-1}$ east wind dominating this area most of the time (see Fig. 3a, where the selected period is marked). The weather was cloud-free, without precipitation. Under this meteorological situation, the pollution in the surface layer was dominated by the local or regional emissions. Thus, the meteorological situation was well suited for the investigation of the diurnal variations of aerosol properties via PartMC-MOSAIC.

\subsection{Description of the simulated cases}

There are several plausible mechanisms to explain the diurnal behaviour of aerosol mixing state, all of which are likely consistent with the measurements described in Sect. 3.2 (Petters et al., 2006; Riemer et al., 2009; Moffet and Prather, 2009; Lance, 2007; Rissler et al., 2006): (1) condensation of secondary organic and inorganic species onto the hydrophobic particles; (2) photochemical oxidation on the surface or in the interior of hydrophobic particles; (3) coagulation of hydrophobic particles with more hygroscopic background particles; (4) the downward mixing by entrainment of more aged, hygroscopic particles from aloft due to the break-up of the nocturnal inversion layer.

The PartMC-MOSAIC model consists of two parts: the PartMC model (Riemer et al., 2009) deals with the coagu-
Table 3. Schemes used in different cases of the PartMC-MOZAIC simulation.

\begin{tabular}{cccc}
\hline case No. & coagulation & $\begin{array}{c}\text { gas, particle } \\
\text { phase chemistries }\end{array}$ & $\begin{array}{c}\text { mixing layer } \\
\text { height }\end{array}$ \\
\hline c1 & off & off & varied \\
c2 & on & off & varied \\
c3 & on & on & varied \\
c4 & on & on & fixed $(1000 \mathrm{~m})$ \\
\hline
\end{tabular}

lation process, particle emissions and dilution in a stochastic manner; while the aerosol chemistry module MOSAIC (Zaveri et al., 2008) simulates the gas and particle phase chemistries, particle phase thermodynamics, and dynamic gas-particle mass transfer deterministically. The effects of these mechanisms on aerosol hygroscopicity and mixing state can be isolated by designing different model simulation cases. We initially assumed $2 \times 10^{4}$ particles in the air parcel for the stochastic simulations. Table 3 shows the experimental design for the mechanism settings used in this study. For case 1, coagulation was switched off in PartMC model, and the MOSAIC chemistry module was disabled in the simulation. Different emission rates of anthropogenic carbonaceous aerosols were set for daytime and nighttime (see Sect. 2.3.2). A variable mixing height (see Fig. 9a) was adapted from the simulation of WRF model (see Sects. 2.3.1 and 2.3.2). Thus, in this case, with condensation, photochemical oxidation and coagulation processes disabled, increases of mixing height and entrainment of air from aloft with a lower concentration of internally mixed aerosols during the morning, resulted in the dilution of surface aerosol concentrations and the change of the overall aerosol mixing state. For case 2, the coagulation process was switched on and other settings were kept the same as case 1 . For case 3, the PartMC model was coupled with the gas-particle chemistry module MOSAIC and others were the same as case 2 , so that all mechanisms mentioned above were considered in the case- 3 simulation. For case 4 , to disable the entrainment of aerosol from aloft in the morning, the mixing height was fixed to $1000 \mathrm{~m}$ (see Fig. 9a) base on case 3 . The evolution of aerosol properties in the air parcel were therefore driven by the aging processes e.g., coagulation, condensation of secondary organic and inorganic species, and photochemical oxidation.

\subsection{Simulated and measured aerosol properties}

The comparison of modelled and measured aerosol properties is shown in the lower two panels of Fig. 9. The modelled external mixed BC and POA (with $\kappa<0.1$ ) are considered to be a proxy for $\mathrm{NH}$ particles and are compared to the modelled total number concentration to yield a modelled nf. The volume-weighted average $\kappa$ for all modelled components is compared to the measured $\kappa_{\text {mean }}$. Both the simulation (case 3 
in which all mechanisms were included) and measurements show that the concentrations of both total aerosol and black carbon are lower during the day than during the night, due to the dilution in the morning when the mixing height increases.

Figure $9 \mathrm{~b}$ and $\mathrm{c}$ show that the diurnal variations of $\mathrm{nf}_{\mathrm{NH}}$ and $\kappa_{\text {mean }}$ for $100 \mathrm{~nm}$ particles measured by the HH-TDMA are very pronounced during our simulation period. The $\mathrm{nf}_{\mathrm{NH}}$ of $100 \mathrm{~nm}$ particles is generally low in the afternoon (about 0 to $10 \%$ ), indicating that most of the aerosol particles are hygroscopic; while the $\mathrm{nf}_{\mathrm{NH}}$ increases rapidly after 18:00 LT when the PBL collapses and the HH-TDMA measurements show clear bi-modal distributions of GF-PDF and $\kappa$-PDF, which indicate that the aerosol particles are externally mixed (see Fig. 9b). The mean $\kappa$ of all groups shows the inverse diurnal pattern. The $\kappa_{\text {mean }}$ for $100 \mathrm{~nm}$ dry diameter particles is about 0.2 during the night, and increases rapidly in the morning to about 0.3 . The diurnal variations of $\mathrm{nf}_{\mathrm{NH}}$ and $\kappa_{\text {mean }}$ of $50 \mathrm{~nm}, 200 \mathrm{~nm}$ and $250 \mathrm{~nm}$ particles are similar to those of $100 \mathrm{~nm}$ particles described above. The diurnal patterns of $\mathrm{nf}_{\mathrm{NH}}$ and $\kappa_{\text {mean }}$ of particles with $100 \mathrm{~nm}$ dry diameter can be well depicted by the PartMC-MOSAIC simulations of case 1, 2 and 3, in which the process of aerosols entrainment from aloft in the morning is included. In contrast, simulation of case 4 has failed to capture these diurnal variations. In case 4, aging processes such as coagulation, condensation and photochemical aging are included, but we assumed a fixed mixing height to prevent the dilution and entrainment of background aerosols in the morning when the actual mixing height is increasing. These results indicate that the entrainment of background aged particles in the morning is decisive in explaining the diurnal cycle of aerosol hygroscopicity and mixing state. In the morning ( 07:00 LT), the increasing mixing height brings a downward entrainment of more aged and hygroscopic particles from aloft leading to the decrease of $\mathrm{nf}_{\mathrm{NH}}$ and increase of $\kappa_{\text {mean }}$; while in the evening (after 18:00 LT) the shallow nocturnal stable layer combined with the local emission of black carbon aerosols (e.g., soot emitted from diesel truck engines during the night) explain the rapid increase of hydrophobic particle fraction and the decrease of the mean hygroscopicity. A similar boundary layer mechanism was suggested by Rissler et al. (2006) to explain the diurnal pattern of number concentration, size distribution and hygroscopic properties for biomass burning aerosols in Amazonia. In this study, we use a particle-resolved aerosol model to estimate the effects of downward mixing of more aged aerosol in the morning hour and confirm that this mechanism is a plausible explanation for the diurnal pattern of aerosol hygroscopicity and mixing state. It is important to note that in the simulations we assume the aerosols above the mixing layer to be an internal mixture of sulphate, $\mathrm{OC}$ and $\mathrm{BC}$. The reasons are that these lofted aerosol particles have undergone longer aging processes compared to those in the surface layer near emission sources and that the aging of lofted aerosol particles may be accelerated by cloud processes. Although we consider that this assumption is reasonable, more

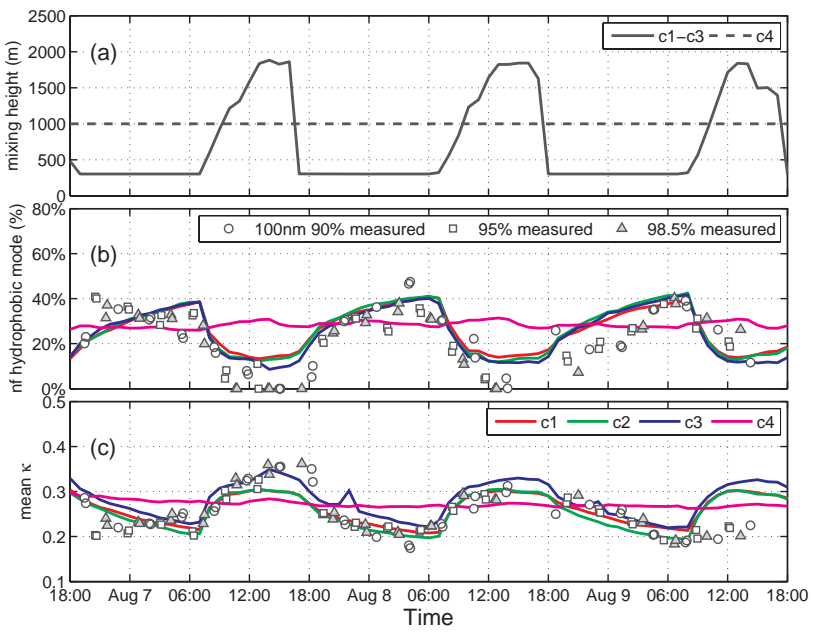

Fig. 9. Comparisons between the PartMC-MOSAIC simulations and the HH-TDMA measurements. (a) Mixing layer height set for different cases; (b) number fraction of nearly-hydrophobic particles; (c) mean hygroscopicity parameter $\kappa$ of all groups. See Table 3 for the settings in the model for the four cases (c1-c4).

three-dimension measurements of aerosol mixing state (e.g., Pratt and Prather, 2010) could be valuable for our scientific understanding.

Comparisons among the results of case 1, 2 and 3 indicate as expected that the aging processes such as coagulation, condensation of organic/inorganic species and photochemical aging also contribute to the variations of the aerosol hygroscopicity and mixing state. Case 2 (with coagulation) demonstrates slightly lower hygroscopicity for $100 \mathrm{~nm}$ particles compared with case 1 . This could be interpreted as the transformation via coagulation of the smaller particles $(\sim 50 \mathrm{~nm})$ which contain large number fraction of fresh soot into larger $(\sim 100 \mathrm{~nm})$ less-hygroscopic particles, resulting in the decrease of mean hygroscopicity measured for $100 \mathrm{~nm}$ particles. Comparison between case 3 and case 2 shows that the condensation and photochemical aging processes could significantly increase the mean hygroscopicity for $100 \mathrm{~nm}$ particles. The chemical aging effects are more pronounced in the afternoon (12:00-18:00 LT) due to the formation of secondary species. However, the chemical aging and coagulation aging are insufficient in explaining the pronounced diurnal variations of mean hygroscopicity and mixing state observed in this study (see Fig. 9b, c).

\section{Conclusions}

For the first time in this geographical and pollution source region of the North China Plain, we employed the HH-TDMA to investigate the atmospheric aerosol and provide a detailed description of its hygroscopic properties and mixing state at high RH between 90 and $98.5 \%$. The measurements were 
conducted from 17 July 2009 to 12 August 2009. These insitu field measurements of atmospheric aerosol are unique with respect to their high RH range and especially of importance to better understand the widespread anthropogenic haze over the North China Plain.

The average GFs of particles with $50-250 \mathrm{~nm}$ dry diameters measured at $90 \%, 95 \%$ and $98.5 \%$ RHs are $1.39-1.57$, $1.57-1.89$ and $1.97-2.70$, respectively. The average GF measured at the same RH generally increased as a function of dry diameter. The corresponding average hygroscopicity parameter $\kappa$ was also determined, ranging from 0.25 to 0.34 for 50 to $250 \mathrm{~nm}$ particles. The average GF-PDF reveals a bi-modal distribution with two distinct peaks and an intermediate transition region. To facilitate the comparison and interpretation of HH-TDMA data measured at different RHs and for different particle size, the inverted GF-PDFs were classified into nearly-hydrophobic $(\kappa<0.1$, first peak), less-hygroscopic $(\kappa=0.1$ to 0.2 , transition) and more-hygroscopic $(\kappa>0.2$, second peak) groups. Based on this classification of hygroscopic groups using the criteria of $\kappa$, the hygroscopic properties measured at different RHs yielded consistent results in terms of $\kappa$, indicating that the $\kappa$-theory is adequate in describing the hygroscopic growth of atmospheric aerosol at a RH range between $90 \%-98.5 \%$. Detailed analysis regarding RH-dependency of $\kappa$ will be presented by Mildenberger et al. (2011). Particles of the more-hygroscopic group are generally dominant for the measured size range of 50 to $250 \mathrm{~nm}$, and the average fraction of the more-hygroscopic group is slightly higher for larger particles, ranging from $68 \%$ to $85 \%$ for 50 to $250 \mathrm{~nm}$ particles. The hygroscopic growth of the more-hygroscopic group was relatively stable during the period, with average $\kappa$ values of 0.30 to 0.39 for 50 to $250 \mathrm{~nm}$ particles. Although the more-hygroscopic atmospheric aerosols reveal lower hygroscopicity than pure ammonium sulphate (with $\kappa=\sim 0.5$ to 0.6 ), these particles experienced large hygroscopic growth at high RH (>90\%), their size being increased by $2.1 \sim 2.8$ fold at $98.5 \% \mathrm{RH}$ as compared to dry particles. These hygroscopic growth behaviours also reveal an immense potential of light scattering enhancement at high humidity and the potential for being highly effective cloud condensation nuclei. For NH group, the average $\kappa$ value of $50 \mathrm{~nm}$ particles was about 0.05 while that for $250 \mathrm{~nm}$ particles was around 0.02 .

The variation of the mean hygroscopicity of all groups is mostly due to the pronounced diurnal pattern for the number fractions of different groups. The average number fraction of nearly-hydrophobic particles during day-time (09:0018:00 LT) is about $8 \%$, while during the night the fraction reaches about $20 \%$. An inverse diurnal pattern of the number fraction of more-hygroscopic particles was correspondingly observed. This variation in number fraction also indicates a change in aerosol mixing state. Based on the spread of $\kappa$-PDF, most of the scans measured during the night demonstrated distinctly external mixing states, while during the day the degree of external mixing was less. A case study for a three day period with stable meteorological conditions was conducted to investigate the diurnal pattern of hygroscopicity and mixing state, using a particle-resolved aerosol model PartMC-MOSAIC. In the case study, the high fraction of nearly-hydrophobic particles during the night was well explained by the shallow nocturnal layer combined with fresh soot emissions from traffic while the rapid decrease in the number fraction of nearly-hydrophobic particles and the corresponding increase in the mean $\kappa$ in the morning hours are mostly due to the entrainment of aged and hygroscopic particles from the residual layer aloft as the stable layer breaks down. The condensation, photochemical aging and coagulation processes are also included in the simulations and they could contribute to the variation of aerosol hygroscopicity and mixing state as expected. However, these aging processes alone were evaluated to be insufficient in magnitude or rate to interpret the observed diurnal pattern of hygroscopicity and mixing state in terms of hygroscopic growth.

Acknowledgements. The authors thank M. Gysel for the use of the TDMA inversion algorithm (TDMAinv). The authors acknowledge N. Riemer, M. West and R. A. Zaveri for their provision and guidance of the PartMC-MOSAIC model. The invaluable comments from D. S. Covert, D. Lamb, J. P. Chan and R. Shaw are also gratefully acknowledged. This work is supported by the National Natural Science Foundation of China (NSFC) under Grant No. 40875001, the German Science Foundation under grant DFG WI 1449/14-1 and the 973 Program (2011CB403402).

Edited by: V.-M. Kerminen

\section{References}

Albrecht, B. A.: Aerosols, cloud microphysics, and fractional cloudiness, Science, 245, 1227-1230, 1989.

Charlson, R. J., Schwartz, S. E., Hales, J. M., Cess, R. D., Coakley Jr., J. A., Hansen, J. E., and Hofmann, D. J.: Climate forcing by anthropogenic aerosols, Science, 255, 423-430, doi:10.1126/science.255.5043.423, 1992.

Cheng, Y. F., Wiedensohler, A., Eichler, H., Heintzenberg, J., Tesche, M., Ansmann, A., Wendisch, M., Su, H., Althausen, D., Herrmann, H., Gnauk, T., Brüggemann, E., Hu, M., and Zhang, Y. H.: Relative humidity dependence of aerosol optical properties and direct radiative forcing in the surface boundary layer at Xinken in Pearl River Delta of China: An observation based numerical study, Atmos. Environ., 42, 6373-6397, 2008.

Deng, Z. Z., Zhao, C. S., Zhang, Q., Huang, M. Y., and Ma, X. C.: Statistical analysis of microphysical properties and the parameterization of effective radius of warm clouds in Beijing area, Atmos. Res., 93, 888-896, 2009.

Deng, Z. Z., Zhao, C. S., Ma, N., Liu, P. F., Ran, L., Xu, W. Y., Chen, J., Liang, Z., Liang, S., Huang, M. Y., Ma, X. C., Zhang, Q., Quan, J. N., Yan, P., Henning, S., Mildenberger, K., Sommerhage, E., Schäfer, M., Stratmann, F., and Wiedensohler, A.: Size-resolved and bulk activation properties of aerosols in the North China plain: the importance of aerosol size distribution in the prediction of $\mathrm{CCN}$ number concentration, Atmos. 
Chem. Phys. Discuss., 11, 1333-1366, doi:10.5194/acpd-111333-2011, 2011.

Eichler, H., Cheng, Y. F., Birmili, W., Nowak, A., Wiedensohler, A., Brüggemann, E., Gnauk, T., Herrmann, H., Althausen, D., Ansmann, A., Engelmann, R., Tesche, M., Wendisch, M., Zhang, Y. H., Hu, M., Liu, S., and Zeng, L. M.: Hygroscopic properties and extinction of aerosol particles at ambient relative humidity in south-eastern China, Atmos. Environ., 42, 6321-6334, 2008.

Göbel, T., Hallbauer, E., Nowak, A., Henning, S., Mildenberger, K., Nekat, B., Ran, L., Liu, P. F., Deng, Z. Z., Ma, N, Zhao, C. S., Covert, D. S., Wiedensohler, A.: Hygroscopic properties of the atmospheric aerosol at high relative humidities from 90 to $99 \%$ determined over the North China Plain during two seasons and its dependency on air mass Origin, Atmos. Chem. Phys. Discuss., in preparation, 2011.

Gysel, M., Crosier, J., Topping, D. O., Whitehead, J. D., Bower, K. N., Cubison, M. J., Williams, P. I., Flynn, M. J., McFiggans, G. B., and Coe, H.: Closure study between chemical composition and hygroscopic growth of aerosol particles during TORCH2, Atmos. Chem. Phys., 7, 6131-6144, doi:10.5194/acp-7-61312007, 2007.

Gysel, M., McFiggans, G. B., and Coe, H.: Inversion of tandem differential mobility analyzer (TDMA) measurements, J. Aerosol Sci., 40, 134-151, doi:10.1016/j.jaerosci.2008.07.013, 2009.

Hennig, T., Massling, A., Brechtel, F. J., and Wiedensohler, A.: A tandem DMA for highly temperature-stabilized hygroscopic particle growth measurements between $90 \%$ and 98\% relative humidity, J. Aerosol Sci., 36, 1210-1223, doi:10.1016/j.jaerosci.2005.01.005, 2005.

Hong, S.-Y., Noh, Y., and Dudhia, J.: A new vertical diffusion package with an explicit treatment of entrainment processes, Mon. Weather Rev., 134, 2318-2341, doi:10.1175/MWR3199.1, 2006.

Jacobson, M. Z.: Strong radiative heating due to the mixing state of black carbon in atmospheric aerosols, Nature, 409, 695-697, 2001.

Köhler, H.: The nucleus in and the growth of hygroscopic droplet, Trans. Faraday Soc., 32, 1152-1161, doi:10.1039/TF9363201152, 1936.

Lance, S.: Quantifying compositional impacts of ambient aerosol on cloud droplet formation, $\mathrm{PhD}$ thesis, School of Earth and Atmospheric Sciences, Georgia Institute of Technology, Atlanta, 166 pp., 2007.

Leitte, A. M., Schlink, U., Herbarth, O., Wiedensohler, A., Pan, X.C., Hu, M., Richter, M., Wehner, B., Tuch, T., Wu, Z., Yang, M., Liu, L., Breitner, S., Cyrys, J., Peters, A., Wichmann, H. E., and Franck, U.: Size-segregated particle number concentrations and respiratory emergency room visits in Beijing, China, Environ. Health Perspect., 119, 508-513, doi:10.1289/ehp.1002203, 2011.

Liu, P. F., Zhao, C. S., Zhang, Q., Deng, Z. Z., Huang, M. Y., Ma, X. C., and Tie, X. X.: Aircraft study of aerosol vertical distributions over Beijing and their optical properties, Tellus B, 61, 756-767, doi:10.1111/j.1600-0889.2009.00440.x, 2009.

Low, R. D. H.: A generalized equation for the solution effect in droplet growth, J. Atmos. Sci., 26, 608-611, 1969.

Ma, N., Zhao, C. S., Nowak, A., Müller, T., Pfeifer, S., Cheng, Y. F., Deng, Z. Z., Liu, P. F., Xu, W. Y., Ran, L., Yan, P., Göbel, T., Hallbauer, E., Mildenberger, K., Henning, S., Yu, J., Cheng, L. L., Zhou, X. J., Stratmann, F., and Wiedensohler, A.: Aerosol op- tical properties in the North China Plain during HaChi campaign: an in-situ optical closure study, Atmos. Chem. Phys. Discuss., 11, 9567-9605, doi:10.5194/acpd-11-9567-2011, 2011.

Massling, A., Stock, M., Wehner, B., Wu, Z. J., Hu, M., Brüggemann, E., Gnauk, T., Herrmann, H., and Wiedensohler, A.: Size segregated water uptake of the urban submicrometer aerosol in Beijing, Atmos. Environ., 43, 1578-1589, 2009.

Menon, S., Hansen, J., Nazarenko, L., and Luo, Y.: Climate effects of black carbon aerosols in China and India, Science, 297, 22502253, doi:10.1126/science.1075159, 2002.

Meier, J., Wehner, B., Massling, A., Birmili, W., Nowak, A., Gnauk, T., Brüggemann, E., Herrmann, H., Min, H., and Wiedensohler, A.: Hygroscopic growth of urban aerosol particles in Beijing (China) during wintertime: A comparison of three experimental methods, Atmos. Chem. Phys., 9, 6865-6880, doi:10.5194/acp9-6865-2009, 2009.

Mildenberger, K., Henning, S., Nowak, A., Sommerhage, E., Schäfer, M., Hallbauer, E., Göbel, T., Nekat, B., van Pinxteren, D., Deng, Z. Z., Liu, P. F., Ma, N., Zhao, C. S., Herrmann, H., Wiedensohler, A., and Stratmann, F.: A hygroscopicity closure study for atmospheric aerosol particles in the North China Plain, Atmos. Chem. Phys. Discuss., in preparation, 2011.

Moffet, R. C. and Prather, K. A.: In-situ measurements of the mixing state and optical properties of soot with implications for radiative forcing estimates, P. Natl. Acad. Sci. USA, 106, 11872 11877, doi:10.1073/pnas.0900040106, 2009.

Oshima, N., Koike, M., Zhang, Y., Kondo, Y., Moteki, N., Takegawa, N., and Miyazaki, Y.: Aging of black carbon in outflow from anthropogenic sources using a mixing state resolved model: Model development and evaluation, J. Geophys. Res., 114, D06210, doi:10.1029/2008jd010680, 2009.

Petters, M. D. and Kreidenweis, S. M.: A single parameter representation of hygroscopic growth and cloud condensation nucleus activity, Atmos. Chem. Phys., 7, 1961-1971, doi:10.5194/acp-71961-2007, 2007.

Petters, M. D., Prenni, A. J., Kreidenweis, S. M., DeMott, P. J., Matsunaga, A., Lim, Y. B., and Ziemann, P. J.: Chemical aging and the hydrophobic-to-hydrophilic conversion of carbonaceous aerosol, Geophys. Res. Lett., 33, L24806, doi:10.1029/2006GL027249, 2006.

Petters, M. D., Wex, H., Carrico, C. M., Hallbauer, E., Massling, A., McMeeking, G. R., Poulain, L., Wu, Z., Kreidenweis, S. M., and Stratmann, F.: Towards closing the gap between hygroscopic growth and activation for secondary organic aerosol: Part 2 theoretical approaches, Atmos. Chem. Phys., 9, 3999-4009, doi:10.5194/acp-9-3999-2009, 2009.

Pratt, K. A. and Prather, K. A.: Aircraft measurements of vertical profiles of aerosol mixing states, J. Geophys. Res., 115, D11305, doi:10.1029/2009jd013150, 2010.

Rader, D. J. and McMurry, P. H.: Application of the tandem differential mobility analyser to studies of droplet growth or evaporation, J. Aerosol Sci., 17, 771-787, 1986.

Riemer, N., West, M., Zaveri, R. A., and Easter, R. C.: Simulating the evolution of soot mixing state with a particleresolved aerosol model, J. Geophys. Res., 114, D09202, doi:10.1029/2008jd011073, 2009.

Riemer, N., West, M., Zaveri, R., and Easter, R.: Estimating black carbon aging time-scales with a particle-resolved aerosol model, J. Aerosol Sci., 41, 143-158, 2010. 
Rissler, J., Vestin, A., Swietlicki, E., Fisch, G., Zhou, J., Artaxo, P., and Andreae, M. O.: Size distribution and hygroscopic properties of aerosol particles from dry-season biomass burning in Amazonia, Atmos. Chem. Phys., 6, 471-491, doi:10.5194/acp6-471-2006, 2006.

Rissler, J., Svenningsson, B., Fors, E. O., Bilde, M., and Swietlicki, E.: An evaluation and comparison of cloud condensation nucleus activity models: Predicting particle critical saturation from growth at subsaturation, J. Geophys. Res., 115, D22208, doi:10.1029/2010jd014391, 2010.

Rose, D., Gunthe, S. S., Su, H., Garland, R. M., Yang, H., Berghof, M., Cheng, Y. F., Wehner, B., Achtert, P., Nowak, A., Wiedensohler, A., Takegawa, N., Kondo, Y., Hu, M., Zhang, Y., Andreae, M. O., and Pöschl, U.: Cloud condensation nuclei in polluted air and biomass burning smoke near the megacity Guangzhou, China - Part 2: Size-resolved aerosol chemical composition, diurnal cycles, and externally mixed weakly CCN-active soot particles, Atmos. Chem. Phys., 11, 2817-2836, doi:10.5194/acp-11-2817-2011, 2011.

Sjogren, S., Gysel, M., Weingartner, E., Alfarra, M. R., Duplissy, J., Cozic, J., Crosier, J., Coe, H., and Baltensperger, U.: Hygroscopicity of the submicrometer aerosol at the high-alpine site Jungfraujoch, $3580 \mathrm{~m}$ a.s.L., Switzerland, Atmos. Chem. Phys., 8, 5715-5729, doi:10.5194/acp-8-5715-2008, 2008.

Skamarock, W. C., Klemp, J. B., Dudhia, J., Gill, D. O., Barker, D. M., Wang, W., and Powers, J. G.: A Description of the Advanced Research WRF Version 2, Tech. Rep. NCAR/TN468+STR, NCAR, 2005.

Su, H., Rose, D., Cheng, Y. F., Gunthe, S. S., Massling, A., Stock, M., Wiedensohler, A., Andreae, M. O., and Pöschl, U.: Hygroscopicity distribution concept for measurement data analysis and modeling of aerosol particle mixing state with regard to hygroscopic growth and CCN activation, Atmos. Chem. Phys., 10, 7489-7503, doi:10.5194/acp-10-7489-2010, 2010.

Svenningsson, B., Hansson, H.-C., Wiedensohler, A., Noone, K., Ogren, J., Hallberg, A., and Colvile, R.: Hygroscopic growth of aerosol particles and its influence on nucleation scavenging in cloud: Experimental results from Kleiner Feldberg, J. Atmos. Chem., 19, 129-152, 1994.

Swietlicki, E., Zhou, J., Berg, O. H., Martinsson, B. G., Frank, G., Cederfelt, S.-I., Dusek, U., Berner, A., Birmili, W., Wiedensohler, A., Yuskiewicz, B., and Bower, K. N.: A closure study of sub-micrometer aerosol particle hygroscopic behaviour, Atmos. Res., 50, 205-240, 1999.

Swietlicki, E., Hansson, H.-C., Hämeri, K., Svenningsson, B., Massling, A., McFiggans, G., McMurry, P. H., Petäjä, T., Tunved, P., Gysel, M., Topping, D., Weingartner, E., Baltensperger, U., Rissler, J., Wiedensohler, A., and Kulmala, M.: Hygroscopic properties of submicrometer atmospheric aerosol particles measured with H-TDMA instruments in various environments: a review, Tellus B, 60, 432-469, 2008.

Topping, D. O., McFiggans, G. B., and Coe, H.: A curved multi-component aerosol hygroscopicity model framework: Part 1-Inorganic compounds, Atmos. Chem. Phys., 5, 1205-1222, doi:10.5194/acp-5-1205-2005, 2005a.
Topping, D. O., McFiggans, G. B., and Coe, H.: A curved multicomponent aerosol hygroscopicity model framework: Part 2Including organic compounds, Atmos. Chem. Phys., 5, 12231242, doi:10.5194/acp-5-1223-2005, 2005b.

Tuch, T. M., Haudek, A., Müller, T., Nowak, A., Wex, H., and Wiedensohler, A.: Design and performance of an automatic regenerating adsorption aerosol dryer for continuous operation at monitoring sites, Atmos. Meas. Tech., 2, 417-422, doi:10.5194/amt-2-417-2009, 2009.

Twomey, S.: Pollution and the planetary albedo, Atmos. Environ., 8, 1251-1256, 1974.

Wehner, B., Wiedensohler, A., Tuch, T. M., Wu, Z. J., Hu, M., Slanina, J., and Kiang, C. S.: Variability of the aerosol number size distribution in Beijing, China: New particle formation, dust storms, and high continental background, Geophys. Res. Lett., 31, L22108, doi:10.1029/2004g1021596, 2004.

Wehner, B., Birmili, W., Ditas, F., Wu, Z., Hu, M., Liu, X., Mao, J., Sugimoto, N., and Wiedensohler, A.: Relationships between submicrometer particulate air pollution and air mass history in Beijing, China, 2004-2006, Atmos. Chem. Phys., 8, 6155-6168, doi:10.5194/acp-8-6155-2008, 2008.

Wex, H., Hennig, T., Salma, I., Ocskay, R., Kiselev, A., Henning, S., Massling, A., Wiedensohler, A., and Stratmann, F.: Hygroscopic growth and measured and modeled critical super-saturations of an atmospheric HULIS sample, Geophys. Res. Lett., 34, L02818, doi:10.1029/2006g1028260, 2007.

Wex, H., Petters, M. D., Carrico, C. M., Hallbauer, E., Massling, A., McMeeking, G. R., Poulain, L., Wu, Z., Kreidenweis, S. M., and Stratmann, F.: Towards closing the gap between hygroscopic growth and activation for secondary organic aerosol: Part 1 evidence from measurements, Atmos. Chem. Phys., 9, 3987-3997, doi:10.5194/acp-9-3987-2009, 2009.

Young, K. C. and Warren, A. J.: A reexamination of the derivation of the equilibrium supersaturation curve for soluble particles, J. Atmos. Sci., 49, 1138-1143, 1992.

Zaveri, R. A., Easter, R. C., Fast, J. D., and Peters, L. K.: Model for simulating aerosol interactions and chemistry (MOSAIC), J. Geophys. Res., 113, D13204, doi:10.1029/2007jd008782, 2008.

Zhang, R., Khalizov, A. F., Pagels, J., Zhang, D., Xue, H., and McMurry, P. H.: Variability in morphology, hygroscopicity, and optical properties of soot aerosols during atmospheric processing, P. Natl. Acad. Sci. USA, 105, 10291-10296, 2008.

Zhang, Q. H., Zhang, J. P., and Xue, H. W.: The challenge of improving visibility in Beijing, Atmos. Chem. Phys., 10, 78217827, doi:10.5194/acp-10-7821-2010, 2010.

Zhao, C., Tie, X., Brasseur, G., Noone, K. J., Nakajima, T., Zhang, Q., Zhang, R., Huang, M., Duan, Y., Li, G., and Ishizaka, Y.: Aircraft measurements of cloud droplet spectral dispersion and implications for indirect aerosol radiative forcing, Geophys. Res. Lett., 33, L16809, doi:10.1029/2006g1026653, 2006a.

Zhao, C., Tie, X., and Lin, Y.: A possible positive feedback of reduction of precipitation and increase in aerosols over Eastern Central China, Geophys. Res. Lett., 33, L11814, doi:10.1029/2006gl025959, 2006b. 